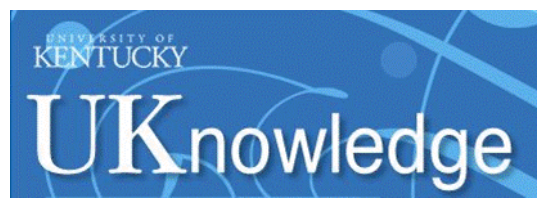

University of Kentucky

UKnowledge

7-20-2017

\title{
Assessing Coastal Plain Risk Indices for Subsurface Phosphorus Loss
}

Amy L. Shober

University of Delaware

Anthony R. Buda

USDA Agricultural Research Service

Kathryn C. Turner

University of Delaware

Nicole M. Fiorellino

Chesapeake College

A. Scott Andres

University of Delaware

See next page for additional authors

Follow this and additional works at: https://uknowledge.uky.edu/pss_facpub

Part of the Environmental Sciences Commons, Plant Sciences Commons, and the Soil Science

Commons

Right click to open a feedback form in a new tab to let us know how this document benefits you.

\section{Repository Citation}

Shober, Amy L.; Buda, Anthony R.; Turner, Kathryn C.; Fiorellino, Nicole M.; Andres, A. Scott; McGrath, Joshua M.; and Sims, J. Thomas, "Assessing Coastal Plain Risk Indices for Subsurface Phosphorus Loss" (2017). Plant and Soil Sciences Faculty Publications. 131.

https://uknowledge.uky.edu/pss_facpub/131

This Article is brought to you for free and open access by the Plant and Soil Sciences at UKnowledge. It has been accepted for inclusion in Plant and Soil Sciences Faculty Publications by an authorized administrator of UKnowledge. For more information, please contact UKnowledge@lsv.uky.edu. 


\section{Assessing Coastal Plain Risk Indices for Subsurface Phosphorus Loss}

Digital Object Identifier (DOI)

https://doi.org/10.2134/jeq2017.03.0102

\section{Notes/Citation Information}

Published in Journal of Environmental Quality, v. 46, no. 6, p. 1270-1286.

Copyright ( American Society of Agronomy, Crop Science Society of America, and Soil Science Society of America.

This is an open access article distributed under the terms of the CC BY-NC-ND license (http://creativecommons.org/licenses/by-nc-nd/4.0/).

\section{Authors}

Amy L. Shober, Anthony R. Buda, Kathryn C. Turner, Nicole M. Fiorellino, A. Scott Andres, Joshua M. McGrath, and J. Thomas Sims 


\title{
Assessing Coastal Plain Risk Indices for Subsurface Phosphorus Loss
}

\author{
Amy L. Shober,* Anthony R. Buda, Kathryn C. Turner, Nicole M. Fiorellino, A. Scott Andres, Joshua M. McGrath, \\ and J. Thomas Sims
}

\begin{abstract}
Phosphorus (P) Index evaluations are critical to advancing nutrient management planning in the United States. However, most assessments until now have focused on the risks of $P$ losses in surface runoff. In artificially drained agroecosystems of the Atlantic Coastal Plain, subsurface flow is the predominant mode of $\mathrm{P}$ transport, but its representation in most $\mathrm{P}$ Indices is often inadequate. We explored methods to evaluate the subsurface $P$ risk routines of five $P$ Indices from Delaware, Maryland (two), Virginia, and North Carolina using available water quality and soils datasets. Relationships between subsurface $P$ risk scores and published dissolved P loads in leachate (Delaware, Maryland, and North Carolina) and ditch drainage (Maryland) were directionally correct and often statistically significant, yet the brevity of the observation periods (weeks to several years) and the limited number of sampling locations precluded a more robust assessment of each P Index. Given the paucity of measured P loss data, we then showed that soil water extractable $P$ concentrations at depths corresponding with the seasonal high water table $\left(W P_{W T}\right)$ could serve as a realistic proxy for subsurface $P$ losses in ditch drainage. The associations between $W P_{W T}$ and subsurface $P$ risk ratings reasonably mirrored those obtained with sparser water quality data. As such, WEP $\mathrm{WT}_{\mathrm{WT}}$ is seen as a valuable metric that offers interim insight into the directionality of subsurface $P$ risk scores when water quality data are inaccessible. In the long term, improved monitoring and modeling of subsurface P losses clearly should enhance the rigor of future P Index appraisals.
\end{abstract}

\section{Core Ideas}

- We evaluated subsurface $P$ routines of five $P$ Indices in artificially drained soils.

- Subsurface $P$ ratings mostly accorded with $P$ loads in leachate and ditch drainage.

- Water extractable $\mathrm{P}$ at the seasonal high water table was a proxy for ditch $\mathrm{P}$ loss.

- Useful P Index predictions hinged on accurate depictions of subsurface water flux.

- Increased monitoring and modeling of subsurface P loss is needed to test $\mathrm{P}$ Indices.

Copyright $\odot$ American Society of Agronomy, Crop Science Society of America, and Soil Science Society of America. 5585 Guilford Rd., Madison, WI 53711 USA.

All rights reserved.

J. Environ. Qual. 46:1270-1286 (2017)

doi:10.2134/jeq2017.03.0102

This is an open access article distributed under the terms of the CC BY-NC-ND

license (http://creativecommons.org/licenses/by-nc-nd/4.0/)

Supplemental material is available online for this article.

Received 8 Mar. 2017.

Accepted 25 May 2017

*Corresponding author (ashober@udel.edu).
T HE Phosphorus (P) Index is an applied site assessment tool that quantifies the risk of $\mathrm{P}$ loss from agriculture by accounting for the principal source and transport factors controlling P flux (Sharpley et al., 2003, 2013). Since its inception in 1993 (Lemunyon and Gilbert, 1993), the P Index concept has expanded to 48 states (Sharpley et al., 2003), with each state taking its own approach to estimating P source and transport risk according to regional differences in hydroclimate, soil properties, and agricultural management. When evaluated separately, P Indices often have produced risk scores that are consistent in direction and magnitude with P fluxes in simulated overland flow (Eghball and Gilley, 2001; DeLaune et al., 2004) and edge-of-field runoff (Harmel et al., 2005; Good et al., 2012). However, when multiple P Indices were benchmarked against common datasets, as was done for 12 southern states by Osmond et al. $(2006,2012)$, the results were less encouraging, with researchers reporting significantly different risk scores among $\mathrm{P}$ Indices for similar P source and transport conditions and differential correspondence between risk scores and P losses in runoff. As a result, there are renewed calls for multistate assessments of $P$ Indices and their components using shared verification datasets across a range of hydrological and management conditions (Sharpley et al., 2013).

To date, most P Index assessments have relied on field measurements of $\mathrm{P}$ loads in surface runoff to corroborate $\mathrm{P}$ risk ratings (Nelson and Shober, 2012). Quantifying P loss in concentrated hydrological flows from runoff plots (McDowell and McGregor, 1980; Pierson et al., 2001; DeLaune et al., 2004; Buda et al., 2009; Sonmez et al., 2009), field edges (Vories et al., 2001; Butler et al., 2010; Good et al., 2012; Williams et al.,

A.L. Shober, K.C. Turner, and J.T. Sims, Dep. of Plant and Soil Sciences, Univ. of Delaware, 531 S. College Ave., Newark, DE 19716; A.R. Buda, USDA-ARS, Pasture Systems and Watershed Management Research Unit, Building 3702, Curtin Rd., University Park, PA 16802-3702; N.M. Fiorellino, Agriculture Dep., Chesapeake College, 1000 College Circle, Wye Mills, MD 21679; A.S. Andres, Delaware Geological Survey, Univ. of Delaware, 257 Academy St., Newark, DE 19716-7501; J.M. McGrath, Univ. of Kentucky, N122-P Ag Science North, Lexington, KY 405460091. Assigned to Associate Editor Deanna Osmond.

Abbreviations: $\mathrm{AM}_{\text {sub }}$ subsurface application method factor; APLE, Annual Phosphorus Loss Estimator; DE-PSI, Delaware Phosphorus Site Index; DPS Mehlich-3 degree of phosphorus saturation; DRP, dissolved reactive phosphorus; MANAGE, Measured Annual Nutrient loads from Agricultural Environments; MDPMT, University of Maryland Phosphorus Management Tool version 1; MD-PMT2, Maryland Phosphorus Management Tool version 2; NC-PLAT, North Carolina Phosphorus Loss Assessment Tool; PSC, phosphorus source coefficient; SD, subsurface drainage factor; $T_{30}$, transmissivity of the soil profile at a depth of 30 to $76 \mathrm{~cm}$; $T_{p}$ transmissivity of the entire profile; TP, total phosphorus application rate; UMES, University of Maryland Eastern Shore; VA-PI, Virginia Phosphorus Index; WEP, water extractable phosphorus; WEP $_{\text {WT }}$, water extractable phosphorus near the water table. 
2017), and small basins (Langdale et al., 1985; Berg et al., 1988; Soileau et al., 1994; Harmel et al., 2005) is a common practice in many experimental watersheds and is relatively uncomplicated; hence, the general reliance on these datasets in P Index verification studies (Nelson and Shober, 2012; Sharpley et al., 2012). Of equal significance is the fact that overland flow is regularly viewed as the primary mode of $\mathrm{P}$ transport on sloping landscapes (Sharpley et al., 1993), making P Index evaluation in these settings fairly straightforward. Thus, with a few exceptions (Vories et al., 2001; Williams et al., 2017), it is not surprising that most runoff datasets underpinning P Index assessment studies hail from upland regions of the Appalachian Highlands and Interior Plains, as well as inland portions of the Atlantic Coastal Plain (Fig. 1), where gently sloping to rolling or hilly topographies ( $\geq 3 \%$ slope) create ideal conditions for P loss by overland flow.

Unlike sloping lands, low-relief agroecosystems with artificial drainage present challenges to P Index assessment. In flat landscapes, shallow subsurface flows often account for a greater portion of water and P flux than surface runoff (King et al., 2015; Kleinman et al., 2015a), requiring P Index components that properly consider the prospect of subsurface $\mathrm{P}$ transport processes (e.g., leaching and groundwater flow). Indeed, 21 out of 48 states have P Indices capable of assessing subsurface P loss risk (Sharpley et al., 2003), and most of these indices are applied in agricultural areas with some degree of artificial drainage (Wieczorek, 2004a, 2004b, 2004c) (Fig. 1). Even so, the subsurface P modules of many P Indices are poorly formulated for use in artificially drained landscapes, especially those with tile lines (Reid et al., 2012). Likewise, the accuracy of subsurface P risk ratings remains relatively unknown because there have been few attempts to verify their predictions against measured subsurface P losses in artificially drained settings (Radcliffe et al., 2015). Recently, Williams et al. (2017) assessed the Ohio P Index using $\mathrm{P}$ loads that were directly measured in edge-of-field runoff and tile drain discharge; however, the Ohio Index lacked a subsurface component, making it difficult to parse the effects of surface versus subsurface $P$ risks. Thus, there is a need to evaluate subsurface $P$ risk routines in P Indices that are used on flat agricultural lands with artificial drainage.

The Delmarva Peninsula exemplifies the challenges of managing subsurface $\mathrm{P}$ loss in agricultural Coastal Plain landscapes with varying intensities of artificial drainage. Vast open ditch networks represent the main type of drainage used on the Delmarva, with tile drainage seen as a minor but increasingly important component. As a rule, intensifying ditch drainage systems by increasing their depth, density, or both tends to amplify water discharge volumes and attendant P transport risks (Skaggs et al., 1994; Blann et al., 2009; Strock et al., 2010). Notably, Kleinman et al. (2007) reported annual P export of 20 to $30 \mathrm{~kg} \mathrm{ha}^{-1}$ from ditches representing some of the most intensively drained sites on the Delmarva Peninsula, with 92\% of these losses attributed to subsurface flow. At these sites, subsurface P losses are mostly driven by $\mathrm{P}$ leaching from $\mathrm{P}$-saturated soils, especially fine-textured soils with macropores (Kleinman et al., 2015a; Toor and Sims, 2015), and interactions between rising groundwater tables and soil horizons with elevated P concentrations (Vadas et al., 2007). Chardon and Schoumans (2007) reported similar P loss pathways in agricultural soils in the lowlands of Belgium, the Netherlands, and Germany. Thus, to adequately represent the risk of subsurface P loss on the Delmarva, P Indices must not only account for $\mathrm{P}$ movement by leaching and shallow subsurface flow (Sims et al., 1998) but also address the role of drainage intensity, a key factor that mediates hydrological connections between subsurface $\mathrm{P}$ transport processes and ditch drainage waters (Staver et al., 2014).

In this paper, we discuss the challenges and opportunities of assessing P Indices in intensively drained agricultural areas of the Delmarva Peninsula. To the best of our knowledge, few, if any, studies have dealt with P Index evaluation in Coastal Plain agroecosystems like the Delmarva, where subsurface P transport processes predominate. We briefly review the subsurface $\mathrm{P}$ risk routines of $\mathrm{P}$ Indices that are commonly applied across the Northern Atlantic Coastal Plain, including the Delaware Phosphorus Site Index (DE-PSI), two versions of the Maryland Phosphorus Management Tool (MD-PMT and MD-PMT2), the Virginia Phosphorus Index (VA-PI), and the North Carolina Phosphorus Loss Assessment Tool (NC-PLAT). We then evaluate the subsurface risk ratings of each P Index against published $P$ export datasets from laboratory leaching experiments and ditch runoff monitoring studies, examine some of the current limitations to using water quality data in P Index assessment, and identify several avenues for future research. Considering the paucity of accessible $\mathrm{P}$ loss data, we introduce and appraise a promising near-term alternative for $P$ Index assessment based on the relationship between ditch P loads and soil water extractable P (WEP) concentrations at depths corresponding to the seasonal high water table $\left(\mathrm{WEP}_{\mathrm{WT}}\right)$. Indeed, we note that assessing Coastal Plain P Indices against a larger and richer soil $\mathrm{P}$ dataset expands our ability to test the veracity of subsurface $\mathrm{P}$ loss predictions that could not otherwise be discerned with limited observations of $\mathrm{P}$ export in drainage waters. In the short term, we recommend that P Index assessments in artificially drained agroecosystems focus on leveraging detailed soil $\mathrm{P}$ datasets when water quality data are inaccessible. In the long term, experiments that quantify subsurface $P$ loss with monitoring and modeling studies are needed to enhance the rigor of future P Index appraisals.

\section{Examining the Subsurface P Risk Routines of Five P Indices Applied on the Atlantic Coastal Plain}

Estimating the risk of subsurface $\mathrm{P}$ loss is an essential structural component of most Atlantic Coastal Plain P Indices, including those used on the Delmarva Peninsula (Fig. 1); New Jersey and New York are the exceptions. In general, these P Indices represent vertical leaching and shallow lateral flow processes, with the latter mechanism necessary to transfer leached $\mathrm{P}$ to ditch drainage waters and streams (Kleinman et al., 2015a). While there is general agreement about the transport pathways that create subsurface P loss risk, the methods and assumptions used to calculate these risks vary greatly among the five P Indices we considered. Approaches range from simple look-up tables of $\mathrm{P}$ transport risk factors (DE-PSI, MD-PMT, MD-PMT2, VA-PI) to quantitative estimations of subsurface flows using hydrologic simulation models (NC-PLAT). The five P Indices also differed structurally, with the DE-PSI arranged as a multiplicative index and the MD-PMT and MD-PMT2, VA-PI, and NC-PLAT formulated 
A.

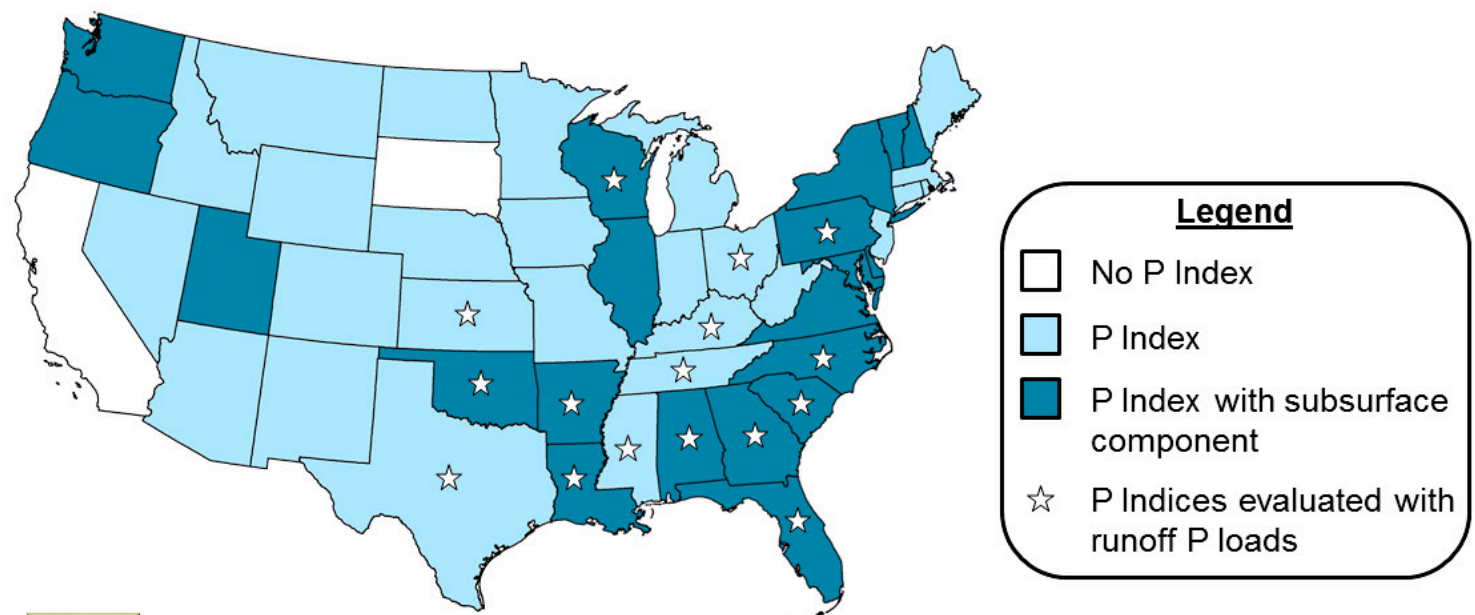

B.

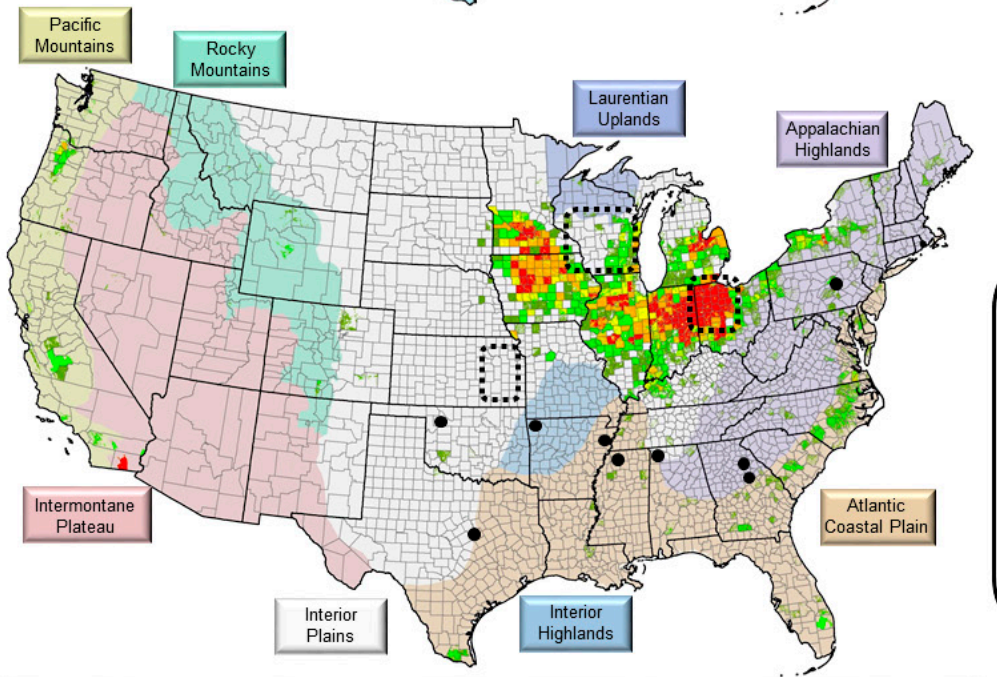

\section{Legend}

- $\quad$ Sites where runoff $P$ loads were monitored for $P$ Index assessment

i.... Area within which multiple sites provided runoff $P$ load data for $P$ Index assessment

\section{${ }_{0}$\begin{tabular}{llll} 
Percent of agricultural land with tile drainage \\
\hline
\end{tabular} 15 25

C.

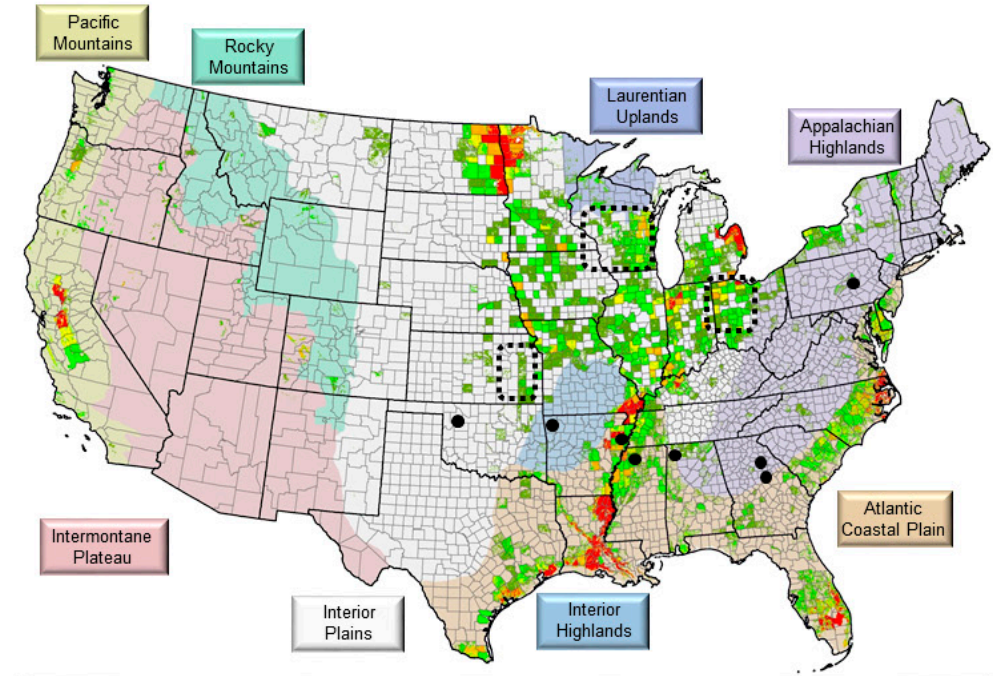

\section{Legend}

- Sites where runoff P loads were monitored for $\mathrm{P}$ Index assessment

Area within which multiple sites provided runoff $\mathrm{P}$ load data for $\mathrm{P}$ Index assessment

Percent of agricultural land with ditch drainage

$$
4
$$

$$
15
$$

Fig. 1. Maps of the United States showing (A) states with $P$ Indices as part of their nutrient management programs, including indices with subsurface components and those that have been assessed against runoff P loads, (B) the percentage of agricultural land in tile drainage across various physiographic regions, and $(C)$ the percentage of agricultural land in ditch drainage across various physiographic regions. Research locations where runoff $\mathrm{P}$ loads have been monitored and used in $\mathrm{P}$ Index assessment are mapped in panels $\mathrm{B}$ and $\mathrm{C}$. 
as component indices. Multiplicative indices, originally conceived by Gburek et al. (2000), produce risk scores that are calculated as the product of independently summed P source (e.g., soil test P, manure and fertilizer soluble $\mathrm{P}$, etc.) and transport (e.g., erosion, distance to water, etc.) factors ( $\Sigma$ source factors $\times \sum$ transport factors $=$ final $\mathrm{P}$ Index score). Component indices differ from the multiplicative approach by separately multiplying $P$ source factors with associated transport processes to assess $P$ loss risk by different pathways of $\mathrm{P}$ movement (i.e., surface runoff, erosion, subsurface flow). Component indices allow a more nuanced view of how $\mathrm{P}$ source and transport processes interact to produce $P$ risk ratings at the field scale (Nelson and Shober, 2012). Because our assessment focused on subsurface P loss and not the overall P Index score, we isolated and evaluated risk scores from each P Index that represented subsurface P risk.

\section{Delaware Phosphorus Site Index}

The DE-PSI is a multiplicative index and therefore does not possess a standalone subsurface P loss component. We estimated subsurface contributions to the total DE-PSI risk score with only the subsurface drainage and leaching factors considered (i.e., no erosion, runoff, or priority of receiving water factors). For the purposes of this study, the DE-PSI subsurface P loss risk score (DE-PSI $I_{\text {sub }}$ ) was calculated as follows:

$$
\begin{aligned}
\text { DE-PSI }_{\text {sub }} & =[\underbrace{\left(\mathrm{SD}_{\text {class }}+\mathrm{LP}\right)}_{\text {transport }} \times \underbrace{0.02}_{\text {scaling }}] \\
\times & \times \underbrace{(0.2 \times \text { Mehlich }-3 \mathrm{P})+\sum(\mathrm{PSC} \times \mathrm{TP})+\mathrm{AM}}_{\text {source }}]
\end{aligned}
$$

where $\mathrm{SD}_{\text {class }}$ is subsurface drainage class (Table 1 ), a semiquantitative rating based on depth to seasonal high water table and soil drainage class; LP is leaching potential, a semiquantitative rating based on depth to seasonal high water table and NRCS leaching index (Table 2); PSC is the P source coefficient for each P source to represent the portion of total $\mathrm{P}$ that is soluble (e.g., 0.5 for poultry litter); TP is the total $\mathrm{P}$ application rate for the $\mathrm{P}$ source $\left(\mathrm{lb} \mathrm{ac}^{-1}\right)$; and $\mathrm{AM}$ is a qualitative $\mathrm{P}$ source application method and timing factor that is based on the time of year and method of application (Sims et al., 2016). From a transport perspective, areas of greatest risk for subsurface P losses tend to be artificially drained locations that are dominated by poorly drained soils with elevated water tables and high leaching potential. Although
Table 2. Soil characteristics (determined by soil survey) used to determine leaching potential for the Delaware P Site Index (Sims et al., 2016). Leaching potential classes include low $(L, 0)$, medium $(M, 2)$, and high $(H, 4)$.

\begin{tabular}{lccc}
\hline $\begin{array}{l}\text { Depth to seasonal } \\
\text { high water table }\end{array}$ & \multicolumn{3}{c}{ Delaware NRCS leaching index for soil series } \\
\cline { 2 - 4 } & $\mathbf{1}$ & $\mathbf{2}$ & $\mathbf{3}$ \\
\hline $0-30 \mathrm{~cm}(0-1 \mathrm{ft})$ & $\mathrm{M}$ & $\mathrm{H}$ & $\mathrm{H}$ \\
$>31-122 \mathrm{~cm}(>1-4 \mathrm{ft})$ & $\mathrm{L}$ & $\mathrm{M}$ & $\mathrm{H}$ \\
$>123-183 \mathrm{~cm}(>4-6 \mathrm{ft})$ & $\mathrm{L}$ & $\mathrm{M}$ & $\mathrm{H}$ \\
$>183 \mathrm{~cm}(>6 \mathrm{ft})$ & $\mathrm{L}$ & $\mathrm{L}$ & $\mathrm{M}$ \\
\hline
\end{tabular}

on-farm research in flat landscapes with artificial drainage has identified poor soil drainage, high water tables, and P leaching as important variables affecting subsurface $P$ loss risk, the lack of field-scale corroboration has precluded objective assessments of their accuracy thus far (Leytem et al., 2003).

\section{Maryland Phosphorus Management Tool Versions 1 and 2}

The operational (MD-PMT) and provisional (MD-PMT2) versions of the Maryland P Management Tool have separate components that estimate the risk of $P$ loss by subsurface flow pathways. In 2013, Maryland shifted from a multiplicative index (which was the same as DE-PSI) to a component index (MD-PMT) because they recognized the importance of subsurface P risk on the Coastal Plain. A key disadvantage of multiplicative P Indices is that the summation of transport factors diminishes the individual effects of important pathways like subsurface flow, whereas component $\mathrm{P}$ Indices preserve the relative contribution of subsurface P risk to the total transport score. McGrath et al. (2013) calculated the subsurface $\mathrm{P}$ risk score $\left(\mathrm{MD}^{\mathrm{P} M \mathrm{P}_{\text {sub }}}\right.$ ) of MD-PMT as:

$$
\begin{aligned}
& \text { MD-PMT }_{\text {sub }}= \\
& \underbrace{\mathrm{SD}}_{\text {transport }} \times[\underbrace{\sum\left(\mathrm{PSC} \times \mathrm{TP} \times \mathrm{AM}_{\text {sub }}\right)+\left(2 \mathrm{DPS}_{\mathrm{M} 3}\right)}_{\text {source }}]
\end{aligned}
$$

where $\mathrm{SD}$ is a semiquantitative rating factor based on drainage class and hydrologic soil group (Table 3); PSC is the P source coefficient for each $\mathrm{P}$ source (given as standard values [i.e., 0.5 for poultry litter] or derived from source WEP for source specific values); $\mathrm{TP}$ is the total $\mathrm{P}$ application rate for the $\mathrm{P}$ source; $\mathrm{AM}_{\text {sub }}$ is the subsurface application method factor, which is a qualitative rating based on time of year and method of application (Table 4); and $\mathrm{DPS}_{\mathrm{M} 3}$ is the degree of $\mathrm{P}$ saturation as predicted by Mehlich-3 extractable P, Fe, and Al (Sims et al., 2002).

A revised version of Maryland's tool, MD-PMT2, was recently proposed by University of Maryland scientists (Fiorellino,

\begin{tabular}{|c|c|c|c|c|c|c|c|}
\hline \multirow{2}{*}{$\begin{array}{l}\text { Depth to seasonal high } \\
\text { water table }\end{array}$} & \multicolumn{7}{|c|}{ Soil drainage class } \\
\hline & $\begin{array}{c}\text { Very poorly } \\
\text { drained }\end{array}$ & $\begin{array}{c}\text { Poorly } \\
\text { drained }\end{array}$ & $\begin{array}{c}\text { Somewhat } \\
\text { poorly drained }\end{array}$ & $\begin{array}{l}\text { Moderately } \\
\text { well drained }\end{array}$ & $\begin{array}{c}\text { Well } \\
\text { drained }\end{array}$ & $\begin{array}{c}\text { Somewhat } \\
\text { excessively drained }\end{array}$ & $\begin{array}{c}\text { Excessively } \\
\text { drained }\end{array}$ \\
\hline $0-30 \mathrm{~cm}(0-1 \mathrm{ft})$ & $\mathrm{VH}$ & $\mathrm{VH}$ & $\mathrm{VH}$ & $\mathrm{VH}$ & $\mathrm{VH}$ & & \\
\hline$>31-122 \mathrm{~cm}(>1-4 \mathrm{ft})$ & M & M & M & M & $\mathrm{H}$ & $\mathrm{H}$ & \\
\hline$>123-183 \mathrm{~cm}(>4-6 \mathrm{ft})$ & & L & L & L & M & M & M \\
\hline$>183 \mathrm{~cm}(>6 \mathrm{ft})$ & & & VL & L & L & L & L \\
\hline $\begin{array}{l}\text { Artificial subsurface } \\
\text { drainage (any depth) }\end{array}$ & $\mathrm{H}$ & $\mathrm{H}$ & $\mathrm{H}$ & $\mathrm{H}$ & $\mathrm{H}$ & $\mathrm{H}$ & $\mathrm{H}$ \\
\hline
\end{tabular}

Table 1. Site conditions (derived from soil survey data) considered to determine the categorical subsurface $P$ loss risk rating (SD ${ }_{\text {class }}$ ) for use in the Delaware P Site Index score calculation (Sims et al., 2016). Potential subsurface drainage classes include very low (VL, 0), low (L, 2), medium (M, 4), high $(H, 6)$, and very high $(\mathrm{VH}, 8)$. 
Table 3. Subsurface drainage transport factor (SD) used in calculation of the subsurface $\mathrm{P}$ loss risk scores for two iterations of the Maryland Phosphorus Management Tool (MD-PMT sub $_{\text {and }}$ MD-PMT2 $2_{\text {sub }}$ ). The SD factor is calculated as a function of the assigned risk factor for soil drainage class divided by the assigned risk factor for hydrologic soil group for the dominant soil type in the field (McGrath et al., 2013; Fiorellino, unpublished data, 2017).

\begin{tabular}{lcccc}
\hline \multirow{2}{*}{ Soil drainage class (risk factor) } & \multicolumn{5}{c}{ Hydrologic soil group (risk factor) } \\
\cline { 2 - 5 } & $\mathbf{A}(1)$ & $\mathbf{B}(1.2)$ & $\mathrm{C}(1.2)$ & $\mathbf{D}(1)$ \\
\hline Very poorly drained (8) & 8.0 & 6.7 & 6.7 & 8.0 \\
Poorly drained (7) & 7.0 & 5.8 & 5.8 & 7.0 \\
Somewhat poorly drained (6) & 6.0 & 5.0 & 5.0 & 6.0 \\
Moderately well drained (5) & 5.0 & 4.2 & 4.2 & 5.0 \\
Well drained (6) & 6.0 & 5.0 & 5.0 & 6.0 \\
Somewhat excessively drained (7) & 7.0 & 5.8 & 5.8 & 7.0 \\
Excessively drained (8) & 8.0 & 6.7 & 6.7 & 8.0 \\
\hline
\end{tabular}

unpublished data, 2017), and this iteration tackles subsurface $P$ risk slightly differently than the MD-PMT:

$$
\mathrm{MD}-\mathrm{PMT} 2_{\text {sub }}=\underbrace{0.259 \mathrm{SD}}_{\text {transport }} \underbrace{\left(\mathrm{DPS}_{\mathrm{M} 3} \times \mathrm{AM}_{\text {sub }}\right) \mathrm{MF}}_{\text {source }}
$$

The SD and $\mathrm{DPS}_{\mathrm{M} 3}$ factors are unchanged from the MD-PMT. The $\mathrm{AM}_{\text {sub }}$ factor was revised to assign a value of one for no manure application; the value increases for various manure application methods and timings (e.g., 1.32 and 1.64 for manure applied between March and November with soil mixing or by broadcast application, respectively; Fiorellino, unpublished data, 2017). The amendment management factor (MF) allows credits for in-ditch filtration of drainage, a practice that is implemented at approximately seven farms in Maryland; the default value for no ditch filter is one. A new scaling factor $(0.259)$ converts DPS to $\mathrm{mg} \mathrm{L}^{-1}$, which is based on published regression relationships with runoff dissolved reactive $\mathrm{P}$ (DRP) reported by Vadas et al. (2005). Notably, the MD-PMT2 $2_{\text {sub }}$ factor does not consider the TP rate or PSC for manure or fertilizers, as was included in the original MD-PMT structure. The TP and PSC factors were moved to new components that account for dissolved P losses from manure (ManureDP) and fertilizer (FertilizerDP); these new factors were not evaluated as part of our study (Fiorellino, unpublished data, 2017). University of Maryland researchers opted to retain the $\mathrm{AM}_{\text {sub }}$ factor to account for the effects of management (manure application and potential incorporation) on the risk of subsurface P loss.

The subsurface components of the Maryland P Indices are used only when manure is applied and artificial drainage is present but are omitted altogether in naturally drained settings. Both indices identify elevated risk of subsurface $P$ loss in areas of rapid infiltration and excessive drainage (i.e., soils prone to leaching) or low infiltration and very poor drainage (i.e., artificially drained soils). Moreover, assessments of MD-PMT and MD-PMT2 in artificially drained soils have indicated that subsurface P risk scores tend to comprise a significant portion of the final $\mathrm{P}$ risk ratings (Fiorellino, unpublished data, 2016). Still, the subsurface $\mathrm{P}$ loss components of MD-PMT and MD-PMT2 have yet to be formally compared with water quality data, although promising evaluations of the surface $P$ loss components of both indices were recently accomplished with the Annual P Loss Estimator (APLE) model (Fiorellino et al., 2017).

\section{Virginia Phosphorus Index}

The VA-PI (Wolfe et al., 2005) assesses the risk of subsurface $\mathrm{P}$ loss via its subsurface risk factor (VA-PI $\mathrm{sub}_{\text {) }}$. Mathematically, VA-PI ${ }_{\text {sub }}$ is expressed as follows:

$$
\begin{aligned}
\text { VA }-\mathrm{PI}_{\text {sub }}= & (\underbrace{\text { Percolation } \times \text { Soil TD factor }}_{\text {transport }} \\
& \times \underbrace{\text { Sub DRP factor }}_{\text {source }} \times \underbrace{0.22651) \times 8.5}_{\text {conversion } / \text { ccaling factors }}
\end{aligned}
$$

where percolation (inches) is derived from annual rainfall less annual runoff (by curve number method; USDA-NRCS, 2004) and annual evapotranspiration; the soil texture and drainage (TD) factor is a qualitative rating based on soil drainage class and soil texture to a depth of $46 \mathrm{~cm}$ (Table 5); and the subsurface dissolved reactive P (Sub DRP) factor represents the potential for dissolved $\mathrm{P}$ loss and is calculated for specific geographical regions using Mehlich-1 soil-test $\mathrm{P}$ data for surface soils $\left(\mathrm{mg} \mathrm{kg}^{-1}\right)$. For the Eastern Shore and Lower Coastal Plain regions in Virginia, subsurface DRP is calculated by the following equation:

$$
\text { Sub DRP factor }=0.2045+(0.0059 \times \text { Mehlich }-1 \mathrm{P})
$$

In essence, the percolation term is used to estimate leaching potential, and soil drainage class and soil texture serve as proxies for artificial drainage, with areas of coarsely textured soils and poor drainage (e.g., soils with high water tables) representing the greatest risk for subsurface P loss. The VA-PI ${ }_{\text {sub }}$ factor does not account for applied P sources (fertilizer or manure). Applied P sources are only considered in the runoff risk component score in the VA-PI (Wolfe et al., 2005). As with DE-PSI, MD-PMT, and MD-PMT2, the subsurface risk factor in VA-PI has not been formally corroborated against $\mathrm{P}$ monitoring data from watershed studies or groundwater samples, although sensitivity analyses showed the subsurface factor to be critically important in artificially drained regions of the Lower Eastern Shore (Jesiek

\begin{tabular}{|c|c|c|}
\hline Application method & MD-PMT & MD-PMT2 \\
\hline None applied & 0.00 & 1.00 \\
\hline Incorporated within $5 \mathrm{~d}$ with soil mixing (precludes straight aerator), Mar.-Nov. & 0.32 & 1.32 \\
\hline Incorporated within $5 \mathrm{~d}$ with soil mixing (precludes straight aerator), Dec.-Feb. & 0.40 & 1.40 \\
\hline $\begin{array}{l}\text { Surface applied and subsurface placement without soil mixing (includes banded fertilizer and injection } \\
\text { without soil mixing), Mar.-Nov. }\end{array}$ & 0.64 & 1.64 \\
\hline $\begin{array}{l}\text { Surface applied and subsurface placement without soil mixing (includes banded fertilizer and injection } \\
\text { without soil mixing), Dec.-Feb. }\end{array}$ & 0.80 & 1.80 \\
\hline
\end{tabular}
and Wolfe, 2005).

Table 4. Application method factor $\left(\mathrm{AM}_{\text {sub }}\right)$ choices used to calculate the subsurface $\mathrm{P}$ loss risk scores for two iterations of the Maryland Phosphorus Management Tool (MD-PMT sub $_{\text {and MD-PMT2 }}$ sub (McGrath et al., 2013; Fiorellino, unpublished data, 2017). 
Table 5. Soil texture and drainage class factor, used in calculation of the subsurface $\mathrm{P}$ loss risk scores for the Virginia Phosphorus Index $\left(\mathrm{VA}-\mathrm{PI} \mathrm{s}_{\text {sub }}\right)$, considers the soil texture to a depth of $46 \mathrm{~cm}$ and the soil drainage class for each soil series (Wolfe et al., 2005).

\begin{tabular}{lccc}
\hline \multirow{2}{*}{ Soil drainage class } & \multicolumn{3}{c}{ Soil texture to depth of $\mathbf{4 6} \mathrm{cm}$} \\
\cline { 2 - 4 } & Coarse† & Medium $\neq$ & Fine§ \\
\hline Very poorly and poorly drained & 1.00 & 0.75 & 0.5 \\
Somewhat poorly drained & 0.25 & 0.25 & 0.00 \\
Moderately well and well drained & 0.00 & 0.00 & 0.00 \\
Somewhat excessively and & & & \\
excessively drained & & & \\
Psamments & 1.00 & 1.00 & 1.00 \\
Udepts or Orthents & 0.50 & 0.50 & 0.50 \\
All other soils & 0.00 & 0.00 & 0.00 \\
\hline
\end{tabular}

† Coarse-textured soils include: coarse sand, sand, fine sand, very fine sand, loamy coarse sand, and loamy sand.

₹ Medium-textured soils include: loamy fine sand, loamy very fine sand, sandy loam, coarse sandy loam, fine sandy loam, very fine sandy loam, loam, silt loam, silt, and sandy clay loam.

$\S$ Fine-textured soils include: clay loam, silty clay loam, sandy clay, silty clay, and clay.

\section{North Carolina Phosphorous Loss Assessment Tool}

In contrast with the semiquantitative approaches used by DE-PSI, MD-PMT, MD-PMT2, and VA-PI, the NC-PLAT uses algorithms and output derived from mechanistic hydrologic models to quantify subsurface drainage volumes and associated P losses. The NC-PLAT subsurface P loss (NC-PLAT ${ }_{\text {sub }}$ ) factor is calculated with the following equation:

$$
\begin{aligned}
& \underbrace{\underbrace{}_{\text {Ne-PLAT }} \text { sub }}= \\
& \underbrace{\text { source }}_{\text {conversion factor }} \text { P concentration } \times \overbrace{\text { Drainage volume }}^{\text {transport }} \\
& \\
& \times(\overbrace{\left(\frac{T_{30}}{T_{\mathrm{P}}}\right)}^{\text {transport }} \times \underbrace{25}_{\text {scaling }}
\end{aligned}
$$

Specifically, leachate $\mathrm{P}$ concentration is a function of Mehlich-3 P concentrations measured at a depth of $76 \mathrm{~cm}$ at sites where the Mehlich-3 P concentration of surface soil samples $(0-20 \mathrm{~cm})$ exceeds 50,100 , or $200 \mathrm{mg} \mathrm{kg}^{-1}$ for organic, sand, and loam soils, respectively. However, the final NC-PLAT risk score is adjusted to the "high" risk category when Mehlich-3 P concentrations at $76-\mathrm{cm}$ depth exceed $50 \mathrm{mg} \mathrm{kg}^{-1}$, which addresses any unforeseen uncertainties associated with the leaching equation in NC-PLAT. Drainage volume is a function of soil drainage condition, with calculations on naturally drained soils based on annual precipitation less runoff volume (by a modified curve number method; USDA-NRCS, 2004) and Groundwater Loading Effects of Agricultural Management Systems (GLEAMS)-simulated evapotranspiration. For artificially drained soils, NC-PLAT estimates drainage volume using drainage intensity (a function of the depth and spacing of ditches and/or tiles and soil profile transmissivity) and several regression coefficients specific to crop, location, and annual precipitation that were derived from long-term DRAINMOD simulations in drained soils of eastern
North Carolina (Johnson, 2004; Skaggs et al., 2004; NC PLAT Committee, 2005). The $T_{30}$ variable represents the transmissivity of the soil profile from 30- to $76-\mathrm{cm}$ depth, and $T_{\mathrm{p}}$ is the transmissivity of the entire soil profile. Collectively, the $T_{30} / T_{\mathrm{p}}$ term indicates the fraction of subsurface flow that moves laterally to drains and ditches through surface soil zones $(0-76 \mathrm{~cm})$, where P enrichment is often most acute (Johnson et al., 2005). The soil transmissivity values are only used to calculate subsurface $P$ risk for artificially drained sites and are omitted in situations where natural drainage prevails (NC PLAT Committee, 2005).

As with the Delmarva P Indices, we sought to implement the native version of NC-PLAT on the lower Delmarva with as little modification as possible, allowing us to test whether the index could be used in artificially drained regions beyond where it was developed. In North Carolina, NC-PLAT runs within the Agricultural Nutrient Assessment Tool software environment, making some of its subroutines considerably less transferrable than the simpler P Indices of Delaware, Maryland, and Virginia. Consequently, we had to transpose the governing equations for NC-PLAT sub to an Excel spreadsheet to estimate subsurface $\mathrm{P}$ risk for ditch-drained sites on the lower Delmarva Peninsula. To ensure that our spreadsheet version of NC-PLAT ${ }_{\text {sub }}$ was accurate, we selected several representative drained locations in eastern North Carolina and successfully compared our predictions against those made by the software version of NC-PLAT. We also note that, although

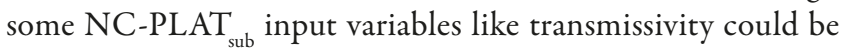
uniquely estimated for Delmarva soils, other parameters used to calculate leachate volumes in artificially drained settings were less easily converted, as they were based on long-term DRAINMOD simulations on representative soil series in eastern North Carolina (Skaggs et al., 2004). Rather than redeveloping these parameters for Delmarva soils using DRAINMOD, which was beyond the scope of our analysis, we opted to use the default regression coefficients and drainage intensity functions provided by NC-PLAT (NC PLAT Committee, 2005) for our sites. On the whole, executing NC-PLAT sub $_{\text {on }}$ on the lower Delmarva offered us a chance to assess findings from studies in North Carolina's Coastal Plain showing that subsurface P risks were generally greatest in coarsely textured sandy soils with high water tables requiring drainage (Johnson et al., 2005; Israel et al., 2007). Moreover, we could evaluate previously expressed concerns about the tendency of NC-PLAT ${ }_{\text {sub }}$ to produce confounding $\mathrm{P}$ loss predictions depending on the type of drainage (natural vs. artificial) assumed for a given location (Johnson et al., 2005).

\section{Assessing Subsurface P Risk Predictions against Water Quality Data from Leaching and Runoff Monitoring Studies}

Observations of average annual $\mathrm{P}$ losses in surface and subsurface runoff are critical to verify the accuracy of P Index predictions. According to several recent reviews of P Indices in the United States (Nelson and Shober, 2012; Sharpley et al., 2012) and Europe (Buczko and Kuchenbuch, 2007), most $P$ Index evaluation studies have tended to focus on total risk scores, with fewer (if any) assessments addressing the reliability 
of $\mathrm{P}$ loss risk ratings assigned by subsurface $\mathrm{P}$ modules. The limited availability of long-term $(>5 \mathrm{yr})$ data on subsurface $\mathrm{P}$ fluxes has clearly hampered efforts to assess subsurface P Index components and scale their ratings across the full spectrum of subsurface P loss risk. Smaller datasets from shorter-term studies that characterize key processes controlling vertical leaching or shallow lateral flow help illustrate some of the barriers to corroborating subsurface P Index components with limited observational data. In the sections that follow, we use published data on P leaching losses and ditch drainage P fluxes to examine the ability of Coastal Plain P Indices to predict subsurface $P$ loss potential from artificially drained settings on the Delmarva Peninsula.

\section{Phosphorus Leaching Datasets}

Measurements of leachate $P$ fluxes are essential for corroborating the accuracy of subsurface $P$ routines in Coastal Plain $P$ Indices, especially those that explicitly rate P leaching risks like DE-PSI and NC-PLAT. The ideal P leaching dataset is one that considers the broadest array of management and soil conditions over the longest possible time. On the Delmarva Peninsula, P leaching loads from agricultural soils have largely been determined via short-term (weeks to months) indoor lysimeter experiments (Feyereisen et al., 2010; Han et al., 2015; Kleinman et al., 2015a; Toor and Sims, 2015). Given these criteria and the aforementioned limitations of measured P loss data, we felt the study by Kleinman et al. (2015a) offered the best opportunity to compare Coastal Plain subsurface P risk scores to P loads in leachate. Kleinman et al. (2015a) evaluated $P$ leaching from eight Delmarva agricultural fields (representing six different soil series; Fig. 2, Supplemental Table S1) over a 17-wk period, including $9 \mathrm{wk}$ before and $8 \mathrm{wk}$ after poultry litter application (applied at total $P$ rate of $52 \mathrm{~kg} \mathrm{ha}^{-1}$ ). All soils had a history of receiving poultry litter under no-till corn (Zea Mays L.) production. Five of the soils were moderately well to well-drained soils with sand to loamy fine sand/sandy loam texture, whereas the sixth soil series was a poorly drained silt loam. Kleinman et al. (2015a) employed intact soil columns $(30-\mathrm{cm}$ diameter $\times 50$-cm height $)$ in a controlled laboratory setting to quantify $\mathrm{P}$ leaching fluxes. The data from Kleinman et al. (2015a) allowed us to draw comparisons between subsurface $P$ risk scores and cumulative leachate $P$ loads from soil P sources (i.e., the 9 -wk period prior to manure application) and manure $\mathrm{P}$ sources (i.e., the 8 -wk period after poultry litter application). Also, we isolated the poorly drained silt loams (Quindocqua soil) in our statistical analysis because P leaching via macropore flow tended to prevail over matrix flow in these soils (Kleinman et al., 2015a); it is widely acknowledged that $\mathrm{P}$ leaching by macropore flow is poorly simulated by most (if not all) P Indices (Reid et al., 2012).

The results of our Coastal Plain P Index assessment showed general consistencies in the accuracy of $\mathrm{P}$ leaching risk predictions on naturally drained soils. Specifically, we found that

\section{Location of Delmarva Peninsula in the US Northeast}

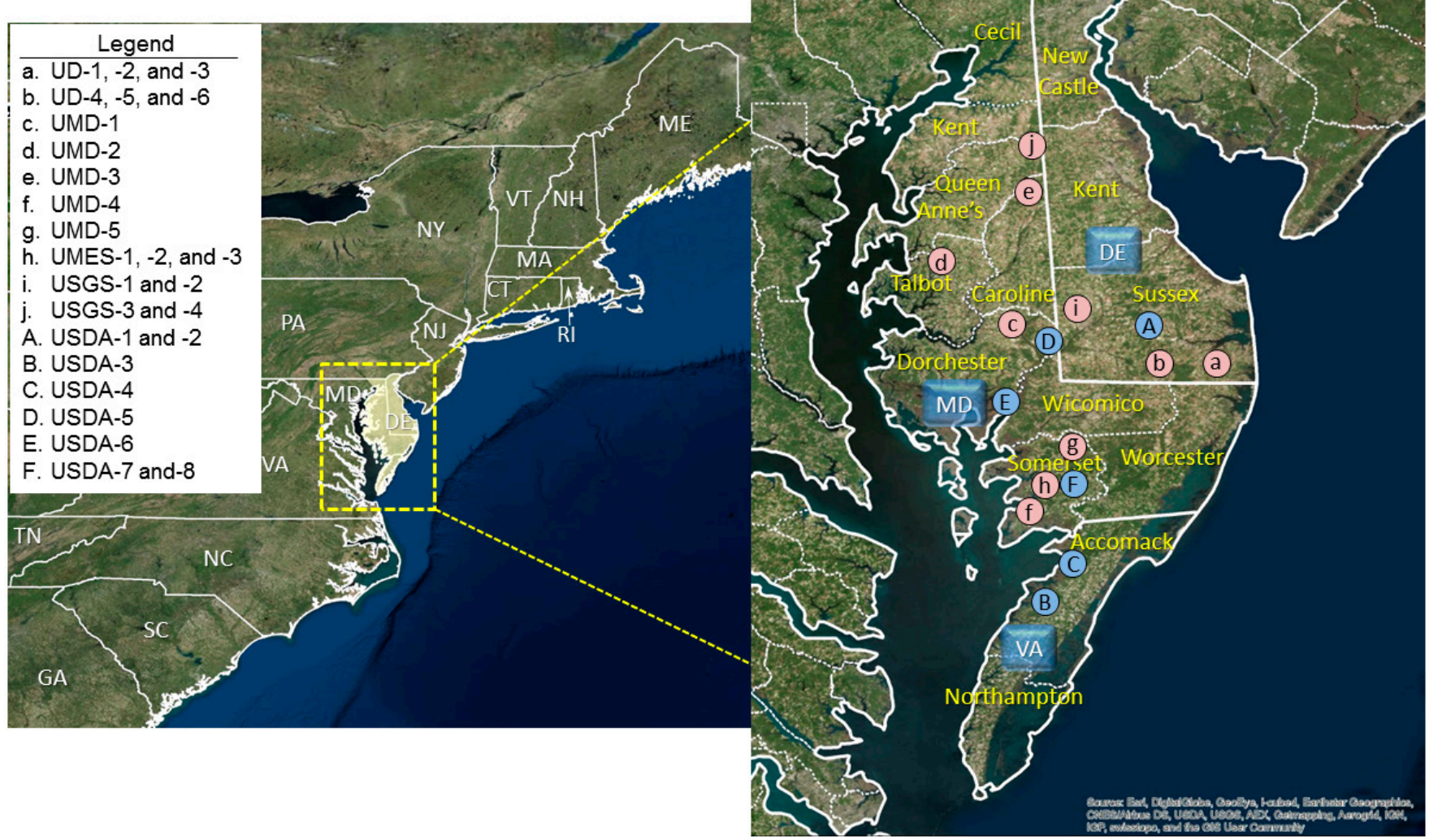

Fig. 2. Location of agricultural fields on the Delmarva Peninsula where intensive dissolved P loads in leachate and ditch water were collected and where soil core sampling was completed. Load data and soil core samples were used to evaluate the subsurface P loss risk assessment methodologies of five regional P Indices, including the Delaware Phosphorus Site Index (DE-PSI), two iterations of the Maryland Phosphorus Management Tool (MD-PMT and MD-PMT2), the North Carolina Phosphorus Loss Assessment Tool (PLAT), and the Virginia Phosphorus Index (VA-PI). 


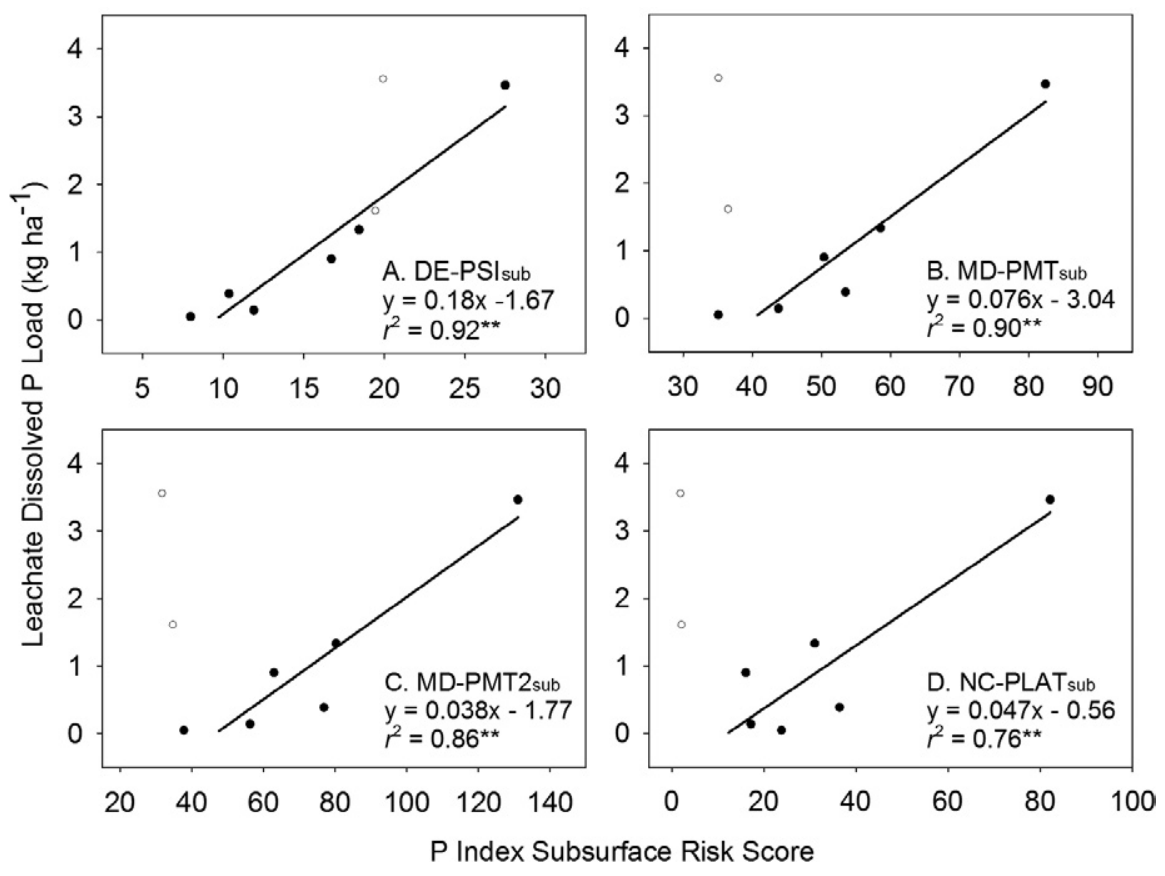

Fig. 3. Relationships between the subsurface $P$ loss risk scores for $(A)$ the Delaware Phosphorus Site Index (DE-PSI sub $^{\text {), (B) the Maryland Phosphorus Management Tool (MD-PMT }}$ sub), (C) the Maryland Phosphorus Management Tool version 2 (MD-PMT2 $2_{\text {sub }}$ ), and (D) the North Carolina Phosphorus Loss Assessment Tool (NC-PLAT ${ }_{\text {sub }}$ ) and dissolved P loads in leachate collected over an 8-wk period after surface poultry litter application (total $P$ rate $=\mathbf{5 2} \mathbf{k g ~ h a}^{-1}$ ) to intact soil columns (Kleinman et al., 2015a). Open circles represent leaching loads from an artificially drained site that were not included in the regression evaluation due to preferential flow in these soils.

DE-PSI $I_{\text {sub }}, M$ D-PMT $T_{\text {sub }}, M D-P M T 2_{\text {sub }}$, and NC-PLAT ${ }_{\text {sub }}$ were significantly $(P<0.014)$ and positively related to dissolved leachate $P$ loads from manure-amended soils experiencing matrix flow, indicating that all four P Indices exhibited the potential to accurately characterize $P$ leaching risks from undrained Coastal Plain soils receiving poultry litter (Fig. 3A-3D). It is also particularly noteworthy that NC-PLAT, through its use of curve number hydrology for leachate volumes and Mehlich-3 soil $\mathrm{P}$ at $76 \mathrm{~cm}$ for leachate $\mathrm{P}$ concentrations, generally captured the magnitude and range of dissolved leachate $\mathrm{P}$ loads from natural drained soils with deep water tables $(>76 \mathrm{~cm})$. Interestingly, the VA-PI ${ }_{\text {sub }}$ assigned values of zero to the five undrained soils used by Kleinman et al. (2015a), indicating an absence of P leaching risk despite measurable $\mathrm{P}$ losses in leachate before and after poultry litter was applied to these soils. Moreover, all P Indices except the VA-PI ${ }_{\text {sub }}$ were able to discern $\mathrm{P}$ leaching risks from edaphic $\mathrm{P}$ sources (i.e., the 9-wk period of $\mathrm{P}$ leaching when no manure was applied). Although the relationships of DE-PSI , MD-PMT $T_{\text {sub }}$, MD-PMT2 $2_{\text {sub }}$, and NC-PLAT ${ }_{\text {sub }}$ with dissolved P loads in leachate were positive and statistically significant $(P<$ 0.015 , Fig. $4 \mathrm{~A}-4 \mathrm{D}$ ), they all were heavily influenced by a single site with high soil-test P. Perhaps the most interesting was the inability of any Coastal Plain P Index to accurately predict the risk of $\mathrm{P}$ leaching from the poorly drained Quindocqua soils, where rapid $\mathrm{P}$ losses by macropore flow generally predominated under artificially drained conditions (Kleinman et al., 2015a; Fig. 3). Thus, although Coastal Plain P Indices seemed to identify a risk of $P$ leaching by matrix flows on naturally drained sites, there remains an urgent need to improve the capacity of these indices to identify and quantify rapid P losses by macropore flow (Reid et al., 2012; Radcliffe et al., 2015).

\section{Phosphorus Fluxes in Ditch Drainage}

Lateral subsurface flow is the principal hydrologic pathway that converts leached $P$ into a surface water pollutant (Kleinman et al., 2015a). Rapid P transport is mainly storm driven and is common in soils with less permeable subsoil horizons that restrict vertical flow occurring near the soil surface. Although rigorous monitoring of $\mathrm{P}$ concentrations and movements in shallow groundwater during storm and interstorm periods has shed important light on the dynamics of subsurface P loss on Maryland's Lower Eastern Shore (Vadas et al., 2007), similarly intensive studies have rarely been replicated elsewhere on the Delmarva. In lieu of directly measuring $\mathrm{P}$ concentrations and water fluxes in shallow lateral flow (which has proven difficult), others have simply applied hydrologic mass balances to indirectly quantify the fraction of ditch P loads attributed to subsurface flow processes. For instance, Kleinman et al. (2007) measured $P$ fluxes in overland flow and in ditch drainage at the University of Maryland Eastern Shore (UMES) and inferred by difference that $92 \%$ of $\mathrm{P}$ losses in drainage waters were due to shallow subsurface flow. Given these findings, we compared Coastal Plain P Index subsurface P risk scores with annual dissolved P load $\left(\mathrm{kg} \mathrm{ha}^{-1}\right)$ data from four ditches draining flat terrain on the Lower Delmarva (Kleinman et al., 2007; Penn et al., 2016; Fig. 2) and a set of dissolved P concentration and discharge measurements $(\sim 1 \mathrm{yr}$ of bimonthly monitoring) from two separate ditches examined by Sims et al. (1996) in the Inland Bays region of southeastern Delaware. A detailed description of methods used to estimate annual dissolved P export from the sites monitored by Sims et al. (1996) is available in the Supplemental Information.

All in all, three of the five Coastal Plain P Indices we tested satisfactorily predicted the risk of subsurface $\mathrm{P}$ loss when ditch dissolved $\mathrm{P}$ loads were used as a proxy for subsurface $\mathrm{P}$ runoff from flat fields with artificial drainage. Although the small size of the dataset ( $n=6$ ditches) likely prohibited significant relationships between subsurface $\mathrm{P}$ risk ratings and dissolved $\mathrm{P}$ loads in ditch drainage, DE-PSI $I_{\text {sub }}$, MD-PMT $T_{\text {sub }}$, MD-PMT2 $2_{\text {sub }}$, and VA-PI sub $_{\text {(to }}$ a lesser extent) all showed that subsurface $P$ loss risk increased concomitantly with dissolved $\mathrm{P}$ losses in ditch drainage (Fig. 5A-5D). Perhaps most important is that the positive relationship between MD-PMT2 ${ }_{\text {sub }}$ and dissolved P loads in ditches (Fig. 5C) was nearly significant at $\alpha=0.1(P=0.12)$, even with only six observations. As such, we suggest that the subsurface drainage factor formulations in semiquantitative P Indices, especially MD-PMT2 $2_{\text {sub }}$ appear to capture the influence of legacy soil $\mathrm{P}$ and intensive ditch drainage on subsurface P risks, although testing these assertions further would require a richer drainage water quality dataset that includes some of the higher ditch dissolved P loads (upward of $\left.20-30 \mathrm{~kg} \mathrm{ha}^{-1}\right)$ that have been observed elsewhere on the Delmarva Peninsula (Kleinman et al., 2007). 
Interestingly, NC-PLAT did not match the apparent success of the Delmarva P Indices in predicting the risk of subsurface $\mathrm{P}$ delivery to ditches, as indicated by the weak negative relationship between NC-PLAT and ditch dissolved P loads (Fig. 5E). Although several key variables and assumptions affect the subsurface P loss calculations by NC-PLAT ${ }_{\text {sub }}$, there are two basic conventions in its subroutines that may lead to an underestimation of subsurface $\mathrm{P}$ risk. To begin with, NC-PLAT ${ }_{\text {sub }}$ uses Mehlich-3 soil P concentrations at $76 \mathrm{~cm}$ to infer leachate $P$ concentrations. In their paper on $\mathrm{P}$ leaching from agricultural soils on the Delmarva Peninsula, Kleinman et al. (2015a) state that leachate $\mathrm{P}$ concentrations in high-P soils are shaped more by Mehlich-3 P concentrations near the soil surface than those measured at depth. Because P concentrations in many Delmarva soils (especially those with artificial drainage and no-till management) are highly stratified, NC-PLAT ${ }_{\text {sub }}$ may be underrating leachate P loads by deriving its leachate $\mathrm{P}$ concentrations solely from subsoil Mehlich-3 P measurements that are likely to be much lower than those near the soil surface. In addition, Johnson et al. (2005) raised a separate but equally important concern about the use of the $T_{30} / T_{\mathrm{p}}$ factor in artificially drained soils (Eq. [6]), noting that it tends to decrease the amount of $\mathrm{P}$ that is lost via subsurface flow despite the expected increases in subsurface discharge volumes that occur with artificial drainage. Functionally, the $T_{30} / T_{\mathrm{p}}$ factor, which typically is a value less than one, restricts the zone in which saturated lateral flows occur to the top $76 \mathrm{~cm}$ of soil, thereby limiting the amount of leached $\mathrm{P}$ that can move laterally to ditches (or tiles), sometimes by as much as $99 \%$. These factors, taken together, underscore the need to further evaluate the $\mathrm{P}$ leaching and lateral flow assumptions made by NC-PLAT so that runoff routing and complex interactions between water and P sources (applied and edaphic) are properly simulated for ditch-drained systems on the Delmarva Peninsula.

\section{Barriers to Assessing P Indices with Observed Data and Future Research Needs}

Assessing the subsurface risk scores of Coastal Plain P Indices with observations of P losses in leachate and ditch drainage was informative, as it enabled a deeper appreciation of the prospects and limitations of expanding such analyses on the Delmarva Peninsula going forward. On one hand, our results were highly encouraging in that relationships between subsurface P risk scores and dissolved P loads were largely positive, and even statistically significant in the case of leachate P. On the other hand, the brevity of the observation periods ( $17 \mathrm{wk}$ for leachate and 1 to $4 \mathrm{yr}$ for ditch drainage) and the limited number of sampling locations clearly impeded a more robust analysis of the Coastal Plain P Indices. According to Sharpley et al. (2013), adequate P Index evaluations require at least 5 to $10 \mathrm{yr}$ of runoff and P concentration data,
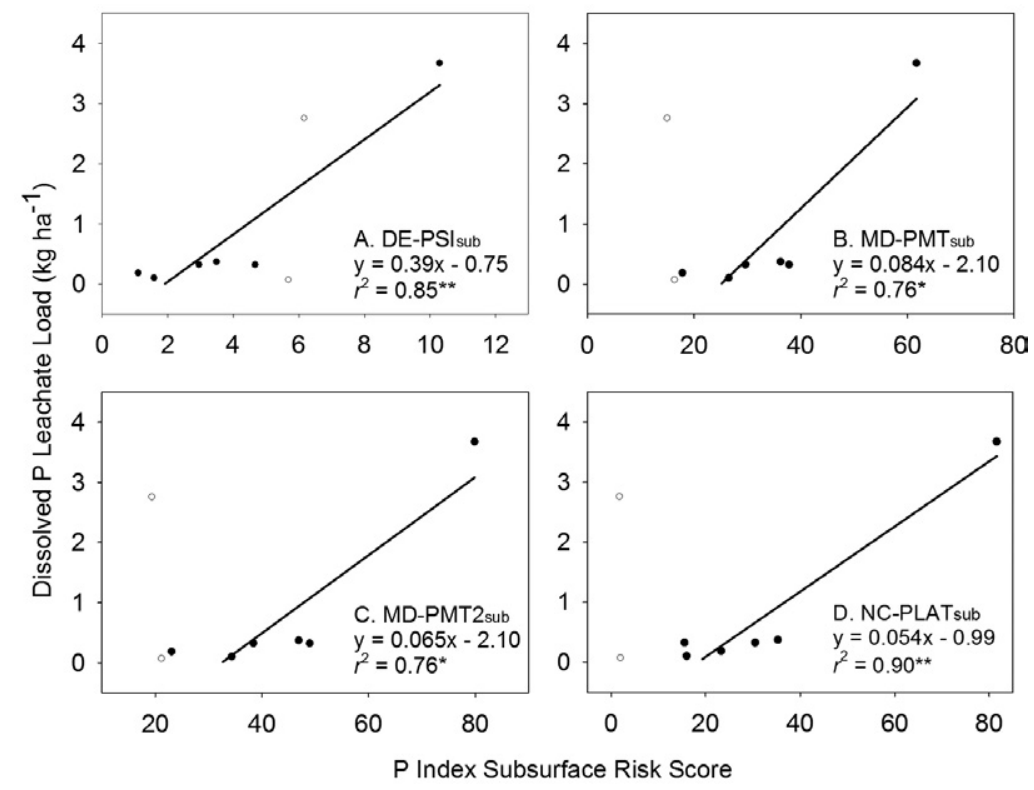

Fig. 4. Relationships between the subsurface $P$ loss risk scores for $(A)$ the Delaware Phosphorus Site Index (DE-PSI sub $_{\text {) }}$, (B) the Maryland Phosphorus Management Tool (MD-PMT sub $_{\text {) }}$ (C) the Maryland Phosphorus Management Tool version 2 (MD-PMT2 $2_{\text {sub }}$ ), and (D) the North Carolina Phosphorus Loss Assessment Tool (NC-PLAT ${ }_{\text {sub }}$ ) and dissolved $P$ loads in leachate from intact soil columns during a 9-wk period of $P$ leaching when no manure was applied (Kleinman et al., 2015a). Open circles represent leaching loads from an artificially drained site that were not included in the regression evaluation due to preferential flow in these soils.

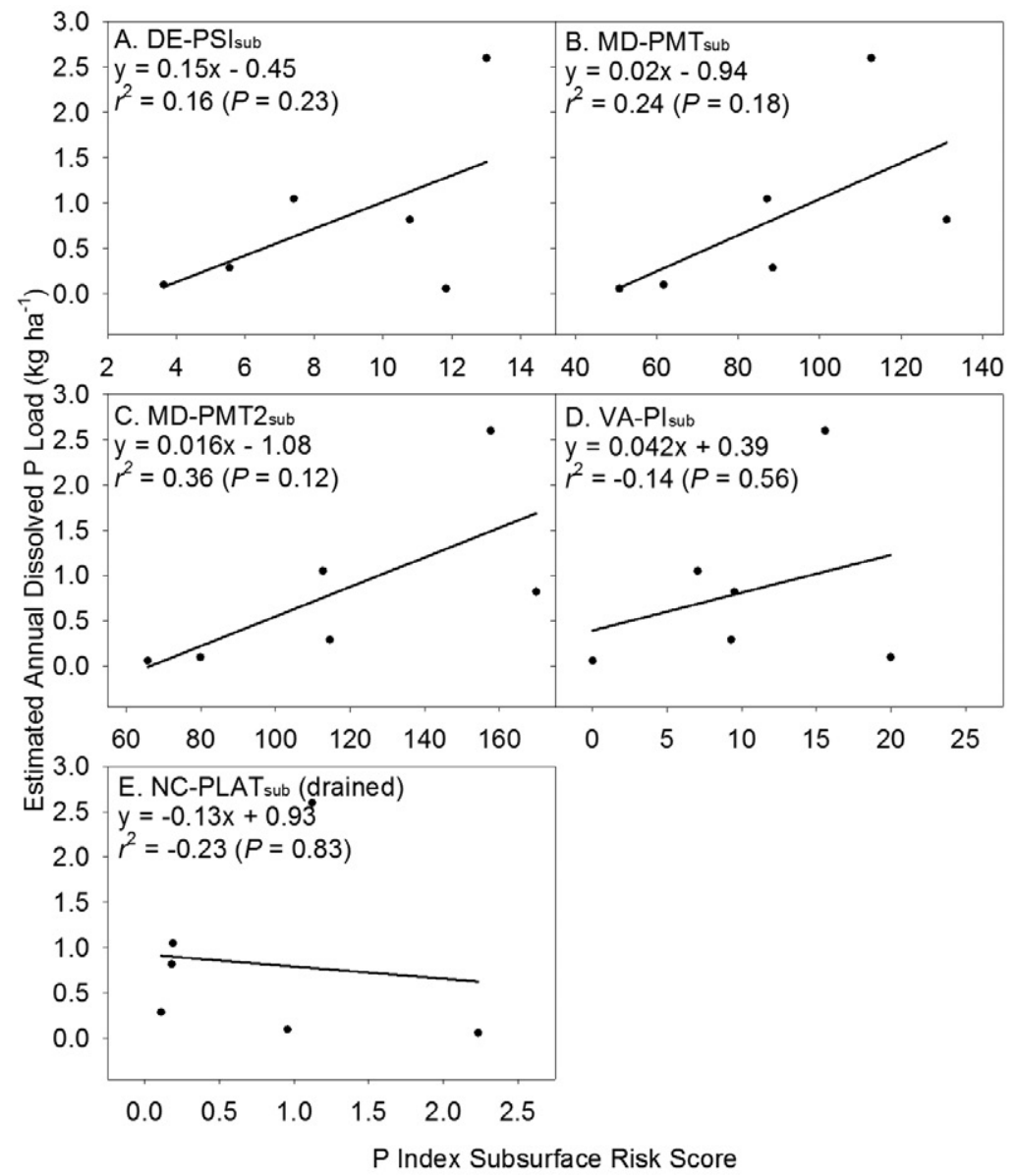

Fig. 5. Relationships between dissolved $\mathrm{P}$ loads in ditch drainage and the subsurface P loss risk scores for (A) the Delaware Phosphorus Site Index (DE-PSI ${ }_{\text {sub }}$ ), (B) the Maryland Phosphorus Management Tool (MD-PMT ${ }_{\text {sub }}$ ), (C) the Maryland Phosphorus Management Tool version 2 (MD-PMT2 $2_{\text {sub }}$ ), and (D) the North Carolina Phosphorus Loss Assessment Tool (NC-PLAT ${ }_{\text {sub }}$ ). 
with shorter observational timeframes and partial event-based datasets seen as less useful. Unfortunately, multiyear measurements of discharge and $\mathrm{P}$ concentrations in ditches and streams on the Delmarva are limited to only a few experimental sites like the Choptank River and the UMES research farm, where ample investments in long-term monitoring have been made. Even fewer estimates of shallow groundwater $P$ fluxes to surface waters are available, owing to the difficulty in measuring and modeling subsurface $\mathrm{P}$ transport over extended areas and timeframes on the Delmarva Peninsula. Of equal significance is the fact that $\mathrm{P}$ leaching studies are rarely done in the field, and those that are performed in the laboratory or greenhouse are not often implemented with P Index verification in mind.

Looking ahead, we need to greatly expand our monitoring of hydrologic flow pathways contributing to $\mathrm{P}$ losses in ditch drainage and make these data more readily available for use in P Index assessments. In terms of data availability, the recent efforts by Christianson et al. (2016) to compile peerviewed datasets on soils, management, and drainage $\mathrm{P}$ losses in the Measured Annual Nutrient loads from Agricultural Environments (MANAGE) database represent a vital first step. The MANAGE database features 1279 site years of published $P$ export data from surface (i.e., ditch) and subsurface (i.e., tile) drainage monitoring studies conducted in 10 states in the southern, Mid-Atlantic, and Midwestern regions of the United States, as well as in two provinces in eastern Canada. While the MANAGE database holds exceptional promise for P Index assessments in tile-drained regions of the US Midwest, its utility for similar studies in ditch-drained settings like the Delmarva Peninsula is more limited. Indeed, only 38 site years of P loss data were derived from drainage ditch monitoring studies, with 15 of those site years coming from one location on Maryland's Lower Eastern Shore (Kleinman et al., 2007; Bryant et al., 2012). The remaining 23 site years represented older research from sites in North Carolina and Florida where soil P and management data needed for P Index assessments were absent, and where geogenic $P$ sources may further confound P Index evaluation. Expanding the MANAGE database to include annual ditch P loads and related field management information from a greater number of sites across the Delmarva Peninsula and similarly flat agroecosystems with artificial ditch drainage should be a high priority for $\mathrm{P}$ Index researchers. We see great potential value in increasing the scope of the MANAGE database to include published datasets from field and laboratory $\mathrm{P}$ leaching studies, as our results using data from Kleinman et al. (2015a) clearly suggest that these data may be beneficial to evaluating and refining $P$ leaching risk modules in Coastal Plain P Indices.

In addition to augmenting the MANAGE database, parallel efforts should also focus on improving the ability of water quality models to simulate P losses from ditch-drained systems. Sharpley (2013) promoted using water quality models to assess $P$ Indices, as these models enable us to extrapolate findings from areas of intensive $\mathrm{P}$ loss measurements to broader regions where such information is insufficient or unavailable (see recent reviews of diffuse P models by Radcliffe et al., 2009; Schoumans et al., 2009). Indeed, using water quality models to expand the spatial and temporal scope of $\mathrm{P}$ loss datasets represents a potential benefit to P Index assessment, and this approach has been used to great effect, especially with simple models like APLE that reliably simulate annual P losses in overland flow (Bolster et al., 2011; Fiorellino et al., 2017). Unfortunately, similar progress in using water quality models to assess and improve the subsurface P risk ratings of $\mathrm{P}$ Indices has yet to be realized, as many models designated for agricultural settings lack the necessary hydrological and biogeochemical routines to accurately simulate subsurface $\mathrm{P}$ fate and transport in artificially drained environments (Kleinman et al., 2015b; Radcliffe et al., 2015). Although many of the best agricultural water quality models struggle in landscapes where structured soils lead to variably saturated and preferential flows, a separate class of models exist with the capability of simulating these complex hydrologic processes at multiple scales (Köhne et al., 2009a, 2009b). An important caveat is that P fate and transport routines specific to agricultural systems need to be incorporated into these models. Thus, there is great need to enhance the ability of physically based hydrologic models to accurately predict $\mathrm{P}$ fluxes in managed agroecosystems. At the same time, improving the reliability of $\mathrm{P}$ transport simulators in artificially drained settings also will be paramount, as exemplified by recent efforts to add macropore flow routines to the Agricultural Policy/ Environmental eXtender (APEX) (Ford et al., 2016), and extend the capacity of the Soil and Water Assessment Tool (SWAT) in tile-drained watersheds (Lu et al., 2016). While this research clearly is important, it will take time to bear fruit. As such, nearterm alternatives to assess P Indices with monitored and modeled water quality data, including (but not limited to) using detailed soil $P$ datasets, should also be considered.

\section{Using Detailed Soil P Data to Evaluate Subsurface P Risk Rating When Water Quality Data Are Sparce}

Soil P datasets hold promise for developing and evaluating subsurface $\mathrm{P}$ risk ratings of Coastal Plain P Indices when the spatial and temporal extent of water quality data are insufficient. The main premise is that $P$ found in soils at depth indicates the potential for subsurface P loss. Because soil testing is central to nutrient management planning, soil P datasets tend to have much broader geographic coverage that enables statewide evaluations of individual P Indices (Coale et al., 2002; Leytem et al., 2003; Fiorellino et al., 2017). Using available soil P data could similarly permit comparisons among multiple P Indices to determine the degree to which their subsurface P risk predictions agree in direction and magnitude. It is particularly important that comparisons use soil $\mathrm{P}$ concentrations at specific depth intervals, as some Coastal Plain P Indices, such as the NC-PLAT, require depth-specific soils data for their calculation. Moreover, these depth-stratified soil P datasets may also lead to new metrics that enable expanded assessments of subsurface P risk. For instance, it is widely acknowledged that $\mathrm{P}$ concentrations in surface runoff are determined, in part, by interactions within the top 0.1 to $4 \mathrm{~cm}$ of soil (Sharpley, 1985). Identifying a similar "effective depth of interaction" in the subsurface that is based on knowledge of potential groundwater connections with subsoil P reservoirs may provide an interim method for estimating the likelihood of subsurface P loss that facilitates the continued development and evaluation of P Indices. 
Examining Predictive Agreement among

\section{Subsurface P Risk Routines}

To test the hypothesis that comprehensive soil $\mathrm{P}$ datasets can facilitate detailed comparisons of subsurface P loss risk scores, we compiled and analyzed a set of 148 soil cores collected by the USGS, University of Delaware, University of Maryland College Park, and UMES between 1995 and 2015 across eight different locations on the lower Delmarva (Fig. 2). The soil cores came from 18 agricultural fields $\left(4-16\right.$ cores field $^{-1}$ ) planted in grain corn. In general, the fields represented a wide range of soil, drainage, and management conditions, including naturally drained sites with and without irrigation and artificially drained locations of varying drainage intensities (Supplemental Tables S2 and S3). Mehlich-3 P concentrations in topsoils $(0-25 \mathrm{~cm})$ ranged from 9.64 to $745 \mathrm{mg}$ $\mathrm{kg}^{-1}\left(\right.$ mean $\left.=256 \mathrm{mg} \mathrm{kg}^{-1}\right)$, reflecting differences in site management history and soil conditions that were broadly consistent with previous studies of agricultural soils across the Delmarva (Sims et al., 2002). For the purposes of our P Index assessment, we treated each of the 148 soil cores as individual field sites when calculating subsurface P risk scores, thereby allowing us to greatly increase the size and scope of our dataset (from 18 fields to 148 hypothetical field sites). We assumed no commercial P fertilizer or manure applications to these sites so that we could isolate the potential risk of P losses driven by "legacy" soil P.

With the notable exception of NC-PLAT ${ }_{\text {sub }}$, our assessment revealed general agreement among the Coastal Plain P Indices regarding a site's propensity for subsurface $\mathrm{P}$ loss. For instance, correlations between MD-PMT $T_{\text {sub }}$, MD-PMT2 $2_{\text {sub }}$, DE-PSI ${ }_{\text {sub }}$, and $\mathrm{VA}_{\text {sub }}$ were all significant and positive (Fig. 6). The strongest correlations occurred between DE-PSI $I_{\text {sub }}$ and MD-PMT2 ${ }_{\text {sub }}$, followed by DE-PSI $I_{\text {sub }}$ with MD-PMT sub $_{\text {, }}$, and DE-PSI ${ }_{\text {sub }}$ with VA-PI ${ }_{\text {sub }}$. The inclusion of soil drainage class as a common factor in DE-PSI $I_{\text {sub }}, M D-P M T_{\text {sub }}, M D-P M T 2_{\text {sub }}$, and VA-PI $I_{\text {sub }}$ likely contributed to the strong associations between these indices. Notably, the VA-PI ${ }_{\text {sub }}$ scores generally partitioned correlations with DE-PSI $I_{\text {sub }}$ into four distinct data clusters (Fig. 6). Three of the data clusters in these sets of correlation plots increased concomitantly in magnitude and direction, which likely accounted for the statistical significance of the correlation coefficients we observed. A large data cluster ( 53 data points), however, showed no correlation between DE-PSI $I_{\text {sub }}$, MD-PMT sub $_{\text {, }}$ and DE-PSI sub $_{\text {with }}$ VA-PI $I_{\text {sub }}$ and instead plotted along the $x$-axis when VA-PI $I_{\text {sub }}$ was the dependent variable. In stark contrast, the weakest correlations were typically noted for NC-PLAT sub $_{\text {. These }}$ results highlight key contrasts between the subsurface P loss predictions of NC-PLAT, a mechanistic P Index, and those made by semiquantitative indices like DE-PSI, MD-PMT, and MD-PMT2.
In addition to differences in directional consistency among Coastal Plain P Indices, we also found substantial discrepancies in the magnitudes of their subsurface P loss risk ratings and their resultant nutrient management recommendations (Fig. 7). Notably, the mean MD-PMT2 2 rub risk score of 107 placed its average site recommendation within the no $\mathrm{P}$ application category before the effects of other index components (i.e., erosion, surface runoff, manure, and fertilizer dissolved P) were even considered. Similarly, 52 of 148 sites were ranked as "high" P risk (no P application) based on the MD-PMT ${ }_{\text {sub }}$ scores (mean score =84). The mean subsurface $\mathrm{P}$ risk scores of other indices were much lower than those of MD-PMT and MD-PMT2, and the recommendations they produced were quite different (for all but three naturally drained soils using NC-PLAT ${ }_{\text {sub }}$ ); namely, a continuation of N-based management. Differences in scaling factors applied to each of subsurface P loss risk predictions likely contributed to the disparate ratings, and it is clear that differences in the magnitude of subsurface P risk scores have significant implications for nutrient management recommendations, especially on the Delmarva, where some fields or farmers operate across state lines (Fiorellino et al., 2017).

\section{Devising and Testing a New Soil-Based Metric to Indicate the Risk of Subsurface P Loss}

In the absence of sufficient water quality data, we also suggest that spatially comprehensive soil P datasets may be an interim

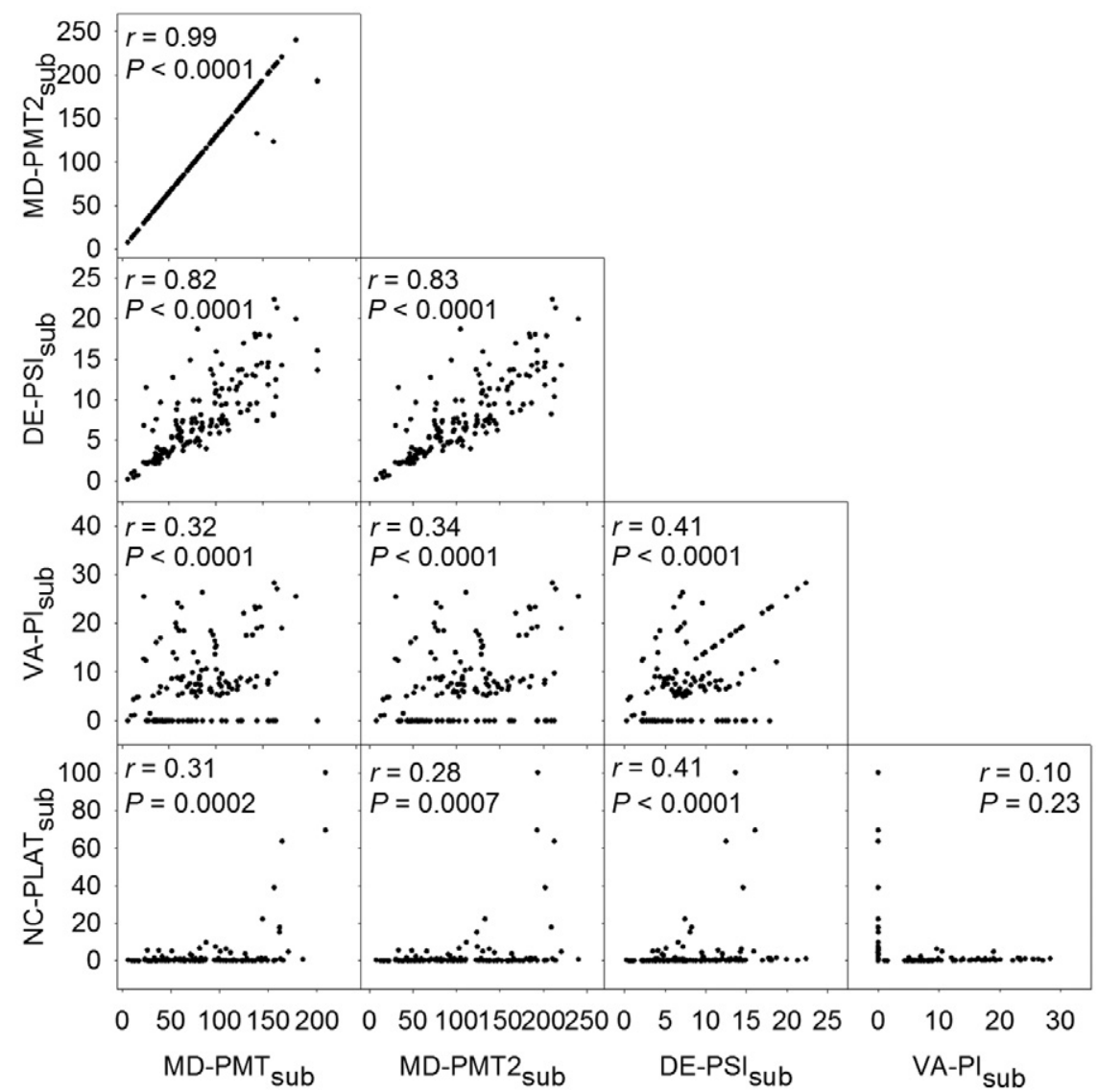

Fig. 6. Pearson correlation matrix showing the relationships between the subsurface $P$ loss risk scores for (A) the Delaware Phosphorus Site Index (DE-PSI ${ }_{\text {sub) }}$ ) (B) the Maryland Phosphorus Management Tool (MD-PMT ), (C) the Maryland Phosphorus Management Tool version 2 (MD-PMT2 $2_{\text {sub) }}$ and (D) the North Carolina Phosphorus Loss Assessment Tool (NC-PLAT ${ }_{\text {sub }}$ ). 
alternative to assessing Coastal Plain P Indices, contingent on some key assumptions. For example, many researchers document the ability of environmental soil $\mathrm{P}$ tests (e.g., WEP or $\mathrm{CaCl}_{2}-$ extractable $\mathrm{P}$ ) to predict $\mathrm{P}$ loss in subsurface flow (McDowell and Sharpley, 2001; Maguire and Sims, 2002; McDowell and Condron, 2004). In addition, researchers suggest that the intersection of groundwater and high soil $\mathrm{P}$ concentrations is a key control on P losses in subsurface flow, including studies by Kleinman et al. (2007) and Vadas et al. (2007) on the lower Delmarva, as well as Obour et al. (2011) in Florida and FloresLópez et al. (2013) in New York. With this evidence in mind, we propose a new metric called $\mathrm{WEP}_{\mathrm{WT}}$, which is the soil WEP concentration at the approximate midpoint depth of the seasonal high water table (determined via the SSURGO database, range $=13-183 \mathrm{~cm}$ across all 148 sites, see the Supplemental Information for more detail). When we compared ditch P loss data from the six ditch locations on the Delmarva Peninsula (Sims et al., 1996; Kleinman et al., 2007; Penn et al., 2016) with $\mathrm{WEP}_{\mathrm{WT}}$ determined from soil cores in their respective field drainage areas, we found a statistically significant relationship (Fig. $8, r^{2}=0.64, P<0.033$ ). As such, we suggest that subsurface $\mathrm{P}$ risk scores from the five Coastal Plain P Indices evaluated in this study should be related to $\mathrm{WEP}_{\mathrm{WT}}$ across all 148 sites when index calculations are based solely on soil P sources (i.e., fields receiving no manure or commercial fertilizer applications).

Interestingly, our assessment of subsurface routines of Coastal Plain P Indices with $\mathrm{WEP}_{\mathrm{WT}}$ generally mirrored the earlier comparisons between ditch $\mathrm{P}$ loads and subsurface $\mathrm{P}$ risk scores. Regression models between soil $\mathrm{WEP}_{\mathrm{WT}}$ and $\mathrm{MD}-\mathrm{PMT}_{\text {sub' }}$, MD-PMT2 ${ }_{\text {sub }}$, DE-PSI sub , and VA-PI $I_{\text {sub }}$ all were significant at $P<$ 0.0001 (Fig. 9), indicating these four $P$ Indices displayed a reasonable ability to evaluate subsurface $\mathrm{P}$ loss risk using $\mathrm{WEP}_{\mathrm{wT}}$. The
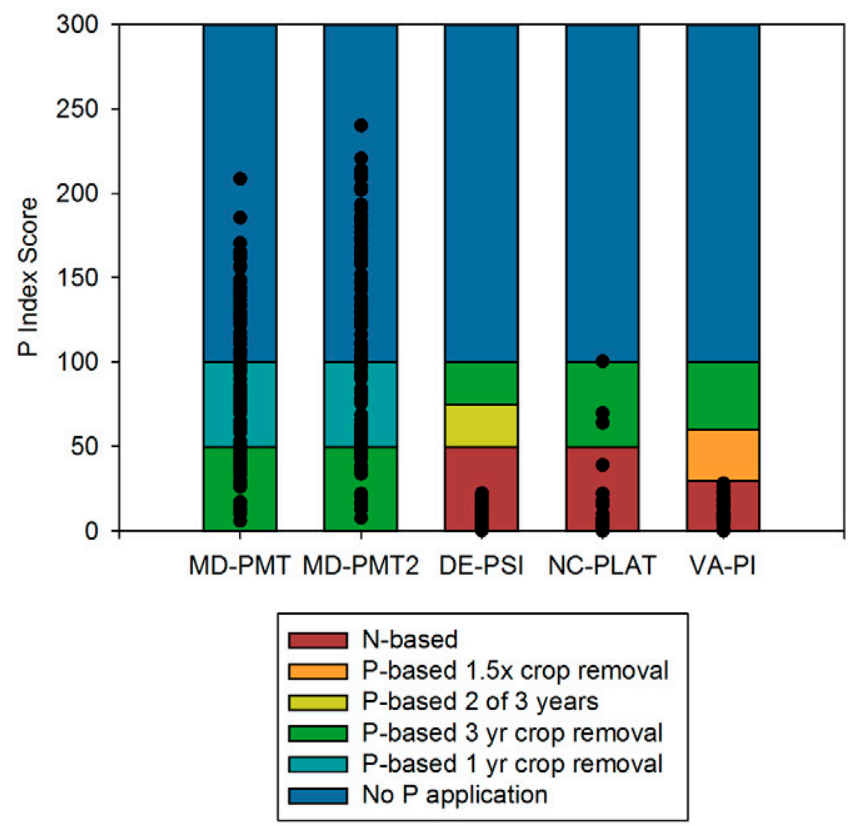

Fig. 7. Comparison of the magnitude and contribution to the total $P$ Index score of subsurface $P$ risk scores (circles) for 148 sites on the Delmarva Peninsula as calculated using five P Indices, including the Delaware Phosphorus Site Index (DE-PSI), two iterations of the Maryland Phosphorus Management Tool (MD-PMT and MD-PMT2), the North Carolina Phosphorus Loss Assessment Tool (PLAT), and the Virginia Phosphorus Index (VA-PI).
MD-PMT2 $2_{\text {sub }}$ exhibited the best capacity to assess subsurface P loss risk on the basis of $\mathrm{WEP}_{\mathrm{WT}}$ across the soils used in this study

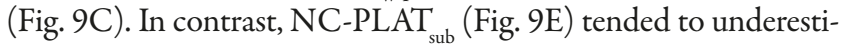
mate $\mathrm{WEP}_{\mathrm{WT}}$ concentrations and associated subsurface $\mathrm{P}$ loss risk at many of the sites where Delmarva P Indices performed well. It is essential to note, however, that NC-PLAT adjusts the final risk score to the "high" risk category when Mehlich-3 P concentrations at $76-\mathrm{cm}$ depth exceed $50 \mathrm{mg} \mathrm{kg}^{-1}$ (NC PLAT Committee, 2005). Even so, this adjustment, which converts a continuous variable to one that is categorical, occurs as part of the total risk score calculation, making it difficult to assess the association between NC-PLAT $T_{\text {sub }}$ and $\mathrm{WEP}_{\mathrm{WT}}$ quantitatively. All in all, similarly successful estimations of $\mathrm{WEP}_{\mathrm{WT}}$ and ditch P loads by Delmarva $\mathrm{P}$ Indices, especially by MD-PMT $\mathrm{T}_{\text {sub }}$ and MD-PMT2 $2_{\text {sub }}$, show that $\mathrm{WEP}_{\mathrm{WT}}$ holds promise as an indicator of the direction of subsurface $P$ risk, which could prove valuable in assessing the subsurface routines of Coastal Plain P Indices in the near term.

\section{Using a Soil-Based Metric to Explore Disparities in Subsurface P Risk Ratings}

We found that differences in the ability of Delmarva P Indices to estimate $\mathrm{WEP}_{\mathrm{WT}}$ concentrations mostly could be attributed to their portrayals of subsurface water flow and accompanying $\mathrm{P}$ loss risk. For instance, the DE-PSI ${ }_{\text {sub }}$ (Sims et al., 2016) includes soil drainage class, NRCS leaching index, and depth to seasonal high water table in two scoring matrices for subsurface drainage and leaching (Supplemental Tables S1 and S2) that in some cases ranked artificially drained sites as "high" risk for subsurface drainage losses (Sims et al., 2016), whereas $\mathrm{WEP}_{\mathrm{WT}}$ concentrations were low. In comparison, the subsurface drainage factor in the MD-PMT $\mathrm{T}_{\text {sub }}$ (McGrath et al., 2013) and MD-PMT2 $2_{\text {sub }}$ (Fiorellino, unpublished data, 2017) uses the less precise hydrologic soil group as a proxy for depth to seasonal high water table (Table 3) and results in the highest subsurface P loss risk under four conditions: (i) excessively drained (high leaching potential) soils with rapid infiltration (low runoff, hydrologic soil group A), (ii) excessively drained (high leaching potential) soils with poor infiltration (high runoff, hydrologic soil group D), (iii)

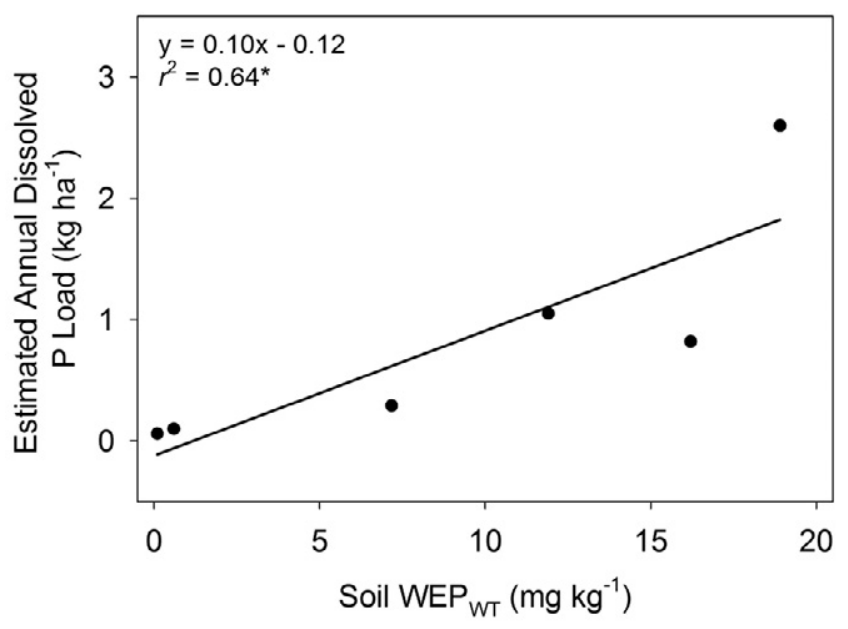

Fig. 8. The relationship between dissolved $P$ loads in ditch drainage from the three locations on the Delmarva Peninsula (Sims et al., 1996; Kleinman et al., 2007; Penn et al., 2016) and soil water extractable $\mathrm{P}$ near the water table $\left(\mathrm{WEP}_{\mathrm{WT}}\right)$ determined from soil cores in their respective field drainage areas. 


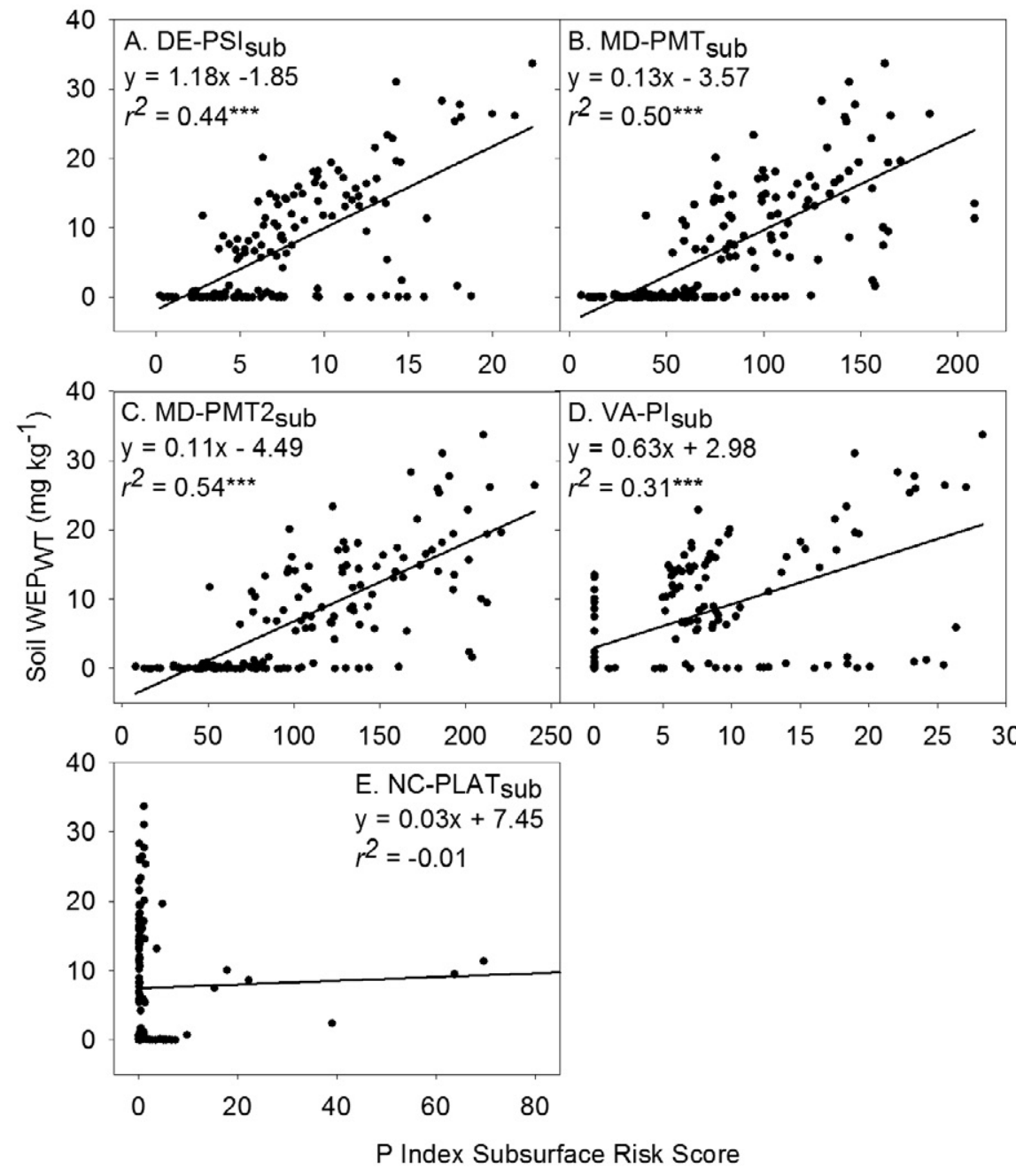

Fig. 9. Linear regression analysis showing relationships between soil water extractable $P$ near the water table $\left(\mathrm{WEP}_{\mathrm{WT}}\right.$ ) and the subsurface $\mathrm{P}$ loss risk scores for $(\mathrm{A})$ the Delaware Phosphorus Site Index (DE-PSI sub' $^{\prime \prime}$ ) (B) the Maryland Phosphorus Management Tool (MD-PMT ${ }_{\text {sub }}$ ), (C) the Maryland Phosphorus Management Tool version 2 (MD-PMT2 $2_{\text {sub) }}$, and (D) the North Carolina Phosphorus Loss Assessment Tool (NC-PLAT ${ }_{\text {sub }}$ ).

very poorly drained (more intense ditch drainage) soils with low infiltration (high runoff, hydrologic soil group D), and (iv) very poorly drained (more intense ditch drainage) soils with high infiltration (low runoff, hydrologic soil group A). These conditions are considered equally risky from the standpoint of subsurface P loss (Table 3), despite the fact that groupings of soil drainage class and hydrologic soil group depicted in scenarios (ii) and (iv) are generally antithetical in their interpretation. As a result, 17 sites with well-drained soils having low to moderate runoff potential were assigned a "medium" (12) or "high" (5) risk of subsurface P losses (MD-PMT $\mathrm{P}_{\text {sub }}>50$ or 100, respectively) when $\mathrm{WEP}_{\mathrm{WT}}$ values were in fact low $\left(<2.41 \mathrm{mg} \mathrm{kg}^{-1}\right.$, Fig. 9B), showing that $\mathrm{MD}-\mathrm{PMT}_{\text {sub }}$ also tends to overrate subsurface $\mathrm{P}$ risk in these settings.

Although VA-PI ${ }_{\text {sub }}$ values were positively related (i.e., directionally consistent) to subsurface P loss risk scores of other Delmarva $\mathrm{P}$ Indices, the correlations were more disjointed. Unlike the P Indices of Maryland and Delaware, VA-PI includes a percolation factor to represent leaching processes and a soil texture and drainage factor to account for the effects of artificial drainage. The VA-PI's soil texture and drainage factor, with categorical values $(1,0.75,0.5,0.25$, or 0$)$ that decline as soil drainage moves from very poorly to excessively drained and as soil texture changes from coarse to fine (Table 5), appeared to account for the highly variable correlation structures observed in Fig. 6; the continuous percolation factor did not. In our study, $52,8,77$, and 12 sites received soil texture and drainage factor scores of $0,0.25,0.75$ and 1, respectively; no sites received a score of 0.5 . Of particular note is the fact that 38 sites had a value of 0 for the soil texture and drainage class factor, as these sites possessed artificial drainage despite having moderately well-drained to well-drained soils with coarse textures. Thus, even though the other Delmarva P Indices assigned some level of subsurface P loss risk to these 38 sites (Supplemental Tables S1 and S2, Fig. 9D), the VA-PI $I_{\text {sub }}$ assigned them negligible risk due to the formulation of the soil texture and drainage factor table. As a result, VA-PI $I_{\text {sub }}$ underestimated $\mathrm{WEP}_{\mathrm{WT}}$ concentrations and subsurface $\mathrm{P}$ loss risk for naturally and artificially drained soils that had measurable Mehlich-3 P and WEP concentrations at depth due to P leaching processes known to occur in these soil types (Kleinman et al., 2015a; Toor and Sims, 2015). Consequently, VA-PI ${ }_{\text {sub }}$ appeared to underrate the risk of subsurface $P$ loss in some situations where higher risks were clearly warranted.

The NC-PLAT ${ }_{\text {sub }}$ score was largely uncorrelated with subsurface risk predictions by Delmarva P Indices and did not seem to capture the potential for lateral subsurface $\mathrm{P}$ loss as indicated by $\mathrm{WEP}_{\mathrm{WT}}$ As we previously noted in comparing NC-PLAT ${ }_{\text {sub }}$ with dissolved P loads in ditches, one or more factors in NC-PLAT ${ }_{\text {sub }}$ caused the index to underestimate subsurface $P$ risk. For instance, over half the sites in our assessment possessed shallow $(<30 \mathrm{~cm})$ water tables that presumably would enable saturated lateral flows to interact with high Mehlich-3 P concentrations near the soil surface, especially during prolonged wet periods. Therefore, inferring leachate $\mathrm{P}$ concentrations with Mehlich-P measurements at $76 \mathrm{~cm}$ may be

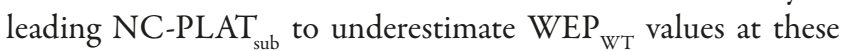
poorly drained locations. Likewise, the use of the $T_{30} / T_{\mathrm{p}}$ factor in Eq. [6] is again notable, as it is only invoked in artificially drained soils (tile drains or ditches) and consequently serves to reduce subsurface $\mathrm{P}$ loss estimations relative to naturally drained sites when all other factors in Eq. [6] are assumed equal (Johnson, 2004). The low NC-PLAT sub score (1.4) for the artificially drained UMES-2 site provides an example of this risk reduction. If the UMES- 2 site had been naturally drained, it would have received a NC-PLAT $T_{\text {sub }}$ score that was nearly 12 times higher (16.6) and more consistent with the elevated mean $\mathrm{WEP}_{\mathrm{WT}}$ 
concentration of $14.0 \mathrm{mg} \mathrm{kg}^{-1}$ in the field and the estimated annual dissolved P loss of $2.6 \mathrm{~kg} \mathrm{ha}^{-1}$ from the receiving drainage ditch. Employing the $T_{30} / T_{\mathrm{p}}$ factor across all 148 artificially drained sites in our study seemingly led NC-PLAT ${ }_{\text {sub }}$ to infer much lower subsurface P loss risk relative to the four Delmarva $P$ Indices (Fig. 9E). These results are remarkably consistent with the earlier comparisons of NC-PLAT ${ }_{\text {sub }}$ with dissolved $\mathrm{P}$ export from field ditches and again point to the need for further testing and refinement of NC-PLAT and its underlying assumptions for use in ditch-drained systems found on the Delmarva Peninsula.

\section{Implication and Conclusions}

Our study sought to address the growing need for P Index testing, which has been articulated in recent papers by Sharpley et al. (2012) and Nelson and Shober (2012), among others. The evaluation of four Midwestern P Indices by Benning and Wortmann (2005) and 12 Southern P Indices by Osmond et al. (2006) clearly demonstrated that disparities in total P Index risk scores can be attributed mainly to the $\mathrm{P}$ source and transport factor formulations of each state, including factor weightings and the method of factor combination (e.g., addition, multiplication, or a mixture of both). In our assessment of Coastal Plain P Indices, we also observed divergent ratings in subsurface $P$ risk scores, particularly when comparing four Delmarva P Indices that used semiquantitative components against NC-PLAT, which relied on more process-based formulations from DRAINMOD. Specifically, we found that the four Delmarva P Indices were generally consistent in their estimations of subsurface $P$ risk and that they fared better in predicting subsurface $\mathrm{P}$ losses using water quality and soils datasets. In contrast, the inability of NC-PLAT to match the successes of the Delmarva P Indices was surprising, especially considering its strong mechanistic underpinnings. Until now, few (if any) studies have sought to address the subsurface component risk scores of several prominent P Indices in isolation. Given the prevalence of $\mathrm{P}$ losses by subsurface flow in artificially drained landscapes of the Delmarva Peninsula, we consider our study an important first step toward confirming the veracity of subsurface $P$ risk predictions by $\mathrm{P}$ Indices used in this region.

One of the central findings of our assessment with water quality data and $\mathrm{WEP}_{\mathrm{WT}}$ metrics was the importance of properly representing water flow in P Indices used to predict subsurface P risk on the Delmarva Peninsula. Interestingly, the default processbased parameters describing water flow in NC-PLAT sub $_{\text {caused it }}$ to frequently underdiagnose the potential for subsurface $\mathrm{P}$ loss in areas of high risk that were better captured by the four Delmarva P Indices. The Delmarva P Indices relied on simple indicators of drainage intensity using common variables in SSURGO data, including seasonal high water table, soil drainage class, and hydrologic soil group. These simple variables generally enabled better predictions of $\mathrm{P}$ fluxes in leachate and ditch drainage, as well as $\mathrm{WEP}_{\mathrm{WT}}$, and highlighted the value of parsimonious methods in P Index applications. Nevertheless, several Delmarva $P$ Indices used varying combinations of SSURGO hydrologic variables, which led them to sometimes overweight or double count the effects of drainage intensity on subsurface P risk. The subsurface drainage matrix in MD-PMT and MD-PMT2 is emblematic of this issue, as it defines several areas of subsurface risk that are occasionally contrasting in their interpretation. To address this, we reformulated the subsurface drainage matrix so that the risk of $\mathrm{P}$ loss was highest in poorly drained soils with high runoff potential and lower in areas with improving drainage and lesser runoff potential (Table 6). When we calculated MD-PMT $\mathrm{Pub}_{\text {sub }}$ with the revised subsurface drainage factor, we found that the prediction of dissolved $\mathrm{P}$ loads in ditch drainage (Fig. 5F) and soil WEP ${ }_{\mathrm{WT}}$ (Fig. 9F) improved by 27\%, suggesting that this reformulation approach may have merit for enhancing the subsurface risk routines of other P Indices commonly used on the Delmarva Peninsula.

A second important finding stemmed from the challenges we faced in applying NC-PLAT sub "as is" to artificially drained regions of the lower Delmarva Peninsula. Unlike the four Delmarva P Indices, which provided relative ratings of subsurface $P$ risk, NC-PLAT relied on mechanistic algorithms to predict $P$ loads in leachate from artificially drained soils, as well as the fraction of those loads that would be susceptible to lateral subsurface transport from fields to ditches (or tiles). Two key assumptions underpinning these calculations were flagged as potential contributors to the underestimation of ditch dissolved $\mathrm{P}$ loads and $\mathrm{WEP}_{\mathrm{WT}}$ by NC-PLAT su, including using Mehlich-3 $\mathrm{P}$ at $76 \mathrm{~cm}$ to infer leachate $\mathrm{P}$ concentrations in artificially drained soils and applying the $T_{30} / T_{\mathrm{p}}$ factor to restrict the zone of saturated lateral flows to the top $76 \mathrm{~cm}$ of soil. To test the lateral transport assumption, we simply removed the $T_{30} / T_{\mathrm{p}}$ factor from Eq. [6] in NC-PLAT $T_{\text {sub }}$ and found little to no improvement in the relationships with ditch dissolved P loads and $\mathrm{WEP}_{\mathrm{WT}}$ (data not shown). Thus, modifying NC-PLAT ${ }_{\text {sub }}$ so that all leached $\mathrm{P}$ was susceptible to lateral transport was insufficient in and of itself to improve its predictions of subsurface $\mathrm{P}$ loss. We then took a different tack by stratifying the depths at which Mehlich-3 P would be expected to control leachate $\mathrm{P}$ concentrations, using Mehlich-3 P values near the soil surface for all artificially drained soils with shallow $(<18 \mathrm{~cm})$ water tables while continuing to use Mehlich-3 P concentrations at $76 \mathrm{~cm}$ for all other soils with deeper water tables. In doing so, we found that this simple change markedly enhanced the ability of NC-PLAT sub $_{\text {to }}$ to determine ditch dissolved P loads and $\mathrm{WEP}_{\mathrm{WT}}$, improving the weakly negative relationships in Fig. 5E and Fig. 9E to significantly positive relationships (Fig. 10B and 10D). Notably, these new relationships between the revised NC-PLAT $T_{\text {sub }}$ and subsurface P loss excluded the $T_{30} / T_{\mathrm{p}}$ factor and thus assumed that all leachate $P$ would move from fields to ditches and/or tile drains. As with the revisions to MD-PMT ${ }_{\text {sub }}$, reassessing some of the assumptions in NC-PLAT sub $_{\text {rug }}$ regarding P leaching

Table 6. Rescaled subsurface drainage transport factor (SD) used in calculation of subsurface $\mathrm{P}$ loss risk scores for two iterations of the Maryland Phosphorus Management Tool (MD-PMT sub $_{\text {and MD-PMT2 }}$ sub $_{\text {). }}$ The SD factor is calculated as a function of the assigned risk factor for soil drainage class divided by the assigned risk factor for hydrologic soil group for the dominant soil type in the field.

\begin{tabular}{lcccc}
\hline \multirow{2}{*}{ Soil drainage class (risk factor) } & \multicolumn{4}{c}{ Hydrologic soil group (risk factor) } \\
\cline { 2 - 5 } & $\mathbf{A}(\mathbf{1 . 6 )}$ & $\mathbf{B}(1.4)$ & $\mathbf{C ~ ( 1 . 2 ) ~}$ & $\mathbf{D ~ ( 1 . 0 )}$ \\
\hline Very poorly drained (7) & 4.4 & 5.0 & 5.8 & 7.0 \\
Poorly drained (6) & 3.8 & 4.3 & 5.0 & 6.0 \\
Somewhat poorly drained (5) & 3.1 & 3.6 & 4.2 & 5.0 \\
Moderately well drained (4) & 2.5 & 2.9 & 3.3 & 4.0 \\
Well drained (3) & 1.9 & 2.1 & 2.5 & 3.0 \\
Somewhat excessively drained (2) & 1.3 & 1.4 & 1.7 & 2.0 \\
Excessively drained (1) & 1.6 & 1.4 & 1.2 & 1.0 \\
\hline
\end{tabular}



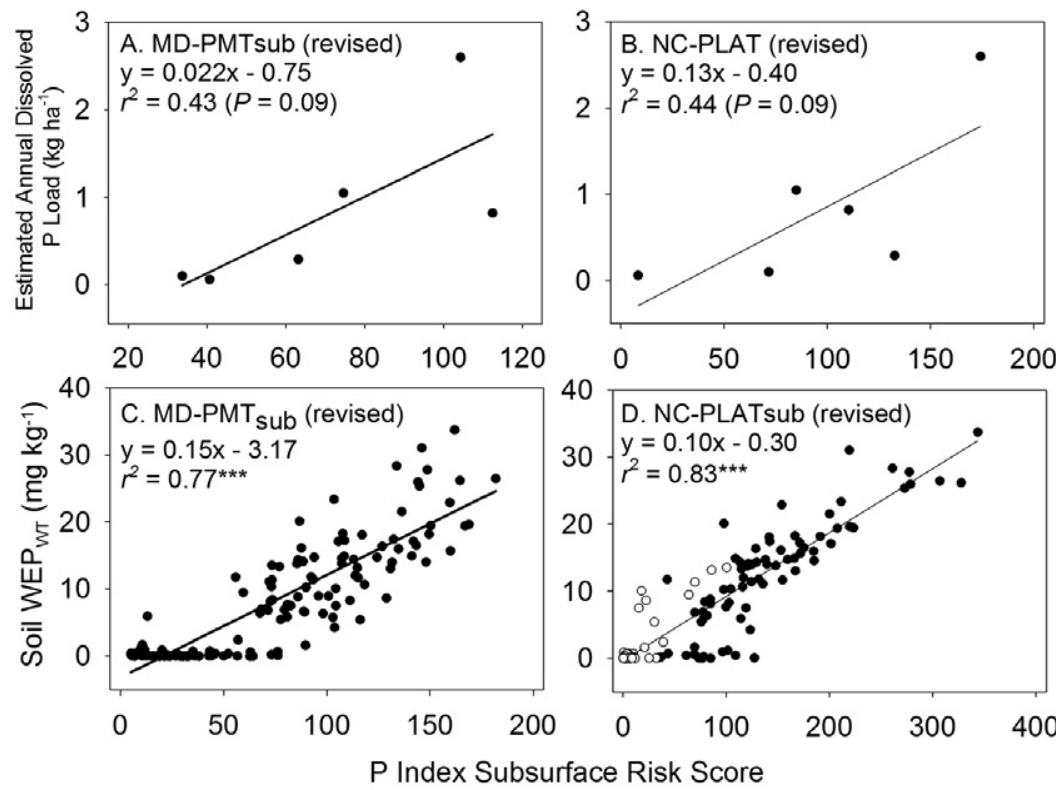

Fig. 10. Graphs showing revised versions of the subsurface $P$ loss risk scores for the Maryland Phosphorus Management Tool (MD-PMT ${ }_{\text {sub }}$ ) and the North Carolina Phosphorus Loss Assessment Tool (NC-PLAT ${ }_{\text {sub }}$ ) plotted against ditch dissolved P loads (A and $B$ ) and soil water extractable $P$ near the water table $\left(W^{2} P_{W T}\right)(C$ and $D)$. Revisions to

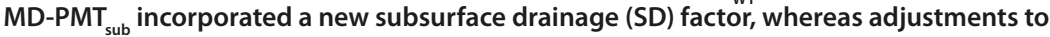
NC-PLAT $T_{\text {sub }}^{\text {sub }}$ ignored the $T_{30} / T_{\mathrm{p}}$ factor, which indicates the fraction of subsurface flow that moves laterally to drains and ditches through surface soil zones, and used Mehlich-3 P concentrations at the surface for soils with shallow water tables $(<18 \mathrm{~cm}$, solid circles) and Mehlich-3 $\mathrm{P}$ concentrations at $76 \mathrm{~cm}$ for soils with deeper water tables $(>18 \mathrm{~cm}$, open circles) to calculate leachate $P$ losses.

and lateral $\mathrm{P}$ transport mechanisms may further enhance its performance in ditch-drained regions of the Delmarva and elsewhere on the Atlantic Coastal Plain.

In terms of our subsurface $\mathrm{P}$ risk calculations based on $\mathrm{WEP}_{\mathrm{wT}}$, we recognize that they more heavily weight edaphic $\mathrm{P}$ sources as opposed to applied P sources, which could be considered a limitation if a P Index is seen only as a decision support tool for manure management. Even in the narrow manure management perspective, however, the relationships between soil $\mathrm{P}$ and runoff $\mathrm{P}$ clearly show that subsurface P loss occurred even without additional manure application. With the exception of the leachate P evaluation in which manure application rates were known (Kleinman et al., 2015a), the lack of detailed manure management data for the remaining study sites required holding manure application practices constant across all sites or simply focusing on soil $P$ as the principal $P$ source to subsurface flow. Even so, we note that detailed manure application data would likely be available in most instances where a P index would be calculated in Delaware and Maryland due to the nutrient management planning and reporting requirements in these states. Nevertheless, our approach and inherent assumptions acknowledge the importance of legacy $\mathrm{P}$ to dissolved $\mathrm{P}$ losses in drainage waters on the Delmarva (Sharpley et al., 2013). We are aware that bias may be imparted by excluding manure sources from our P Index calculations. Accordingly, future P Index assessments of this nature would be strengthened by including detailed information on manure management to test whether $\mathrm{WEP}_{\mathrm{WT}}$ (or similar such soil-based metrics) maintains its utility in P Index appraisals. This is especially true for sites where soil macropores are suspected to be primary conduits for manure $\mathrm{P}$ losses to subsurface drainage, as $\mathrm{WEP}_{\mathrm{WT}}$ probably better represents the risk of dissolved P losses in saturated matrix flows. As new variables or model routines are added to $P$ Indices that better approximate the risk of $\mathrm{P}$ losses by preferential flow, it will be all the more important to consider edaphic and applied $\mathrm{P}$ sources together in subsurface P risk assessment.

In closing, our study highlights some important issues when using water quality and soil $P$ datasets as a means for verifying the subsurface $\mathrm{P}$ loss routines of P Indices. As noted by Sharpley et al. (2012, 2013) and Nelson and Shober (2012), the ideal approach for corroborating P Indices would be to use multiyear observational datasets of $\mathrm{P}$ fluxes in subsurface flows. While we concur with this view, the lack of such datasets on the Delmarva Peninsula led us down an alternate path, where we first highlighted the limits of what can be inferred with $P$ leaching and drainage data and instead showcased the potential value of soil $P$ data at the depth of the seasonal high water table as a suitable surrogate for assessing subsurface $\mathrm{P}$ loss risk. This contention is indeed supported by various studies of $\mathrm{P}$ mobilization processes (McDowell and Sharpley, 2001; Maguire and Sims, 2002; McDowell and Condron, 2004) and subsequent losses in shallow subsurface flow (Kleinman et al., 2007; Vadas et al., 2007; Obour et al., 2011; Flores-López et al., 2013). As such, our results provide interim insight into the predictive ability of subsurface $P$ loss routines in $P$ Indices designed for the Atlantic Coastal Plain, as well as some possible avenues for improving these predictions. Certainly, longer-term efforts should be directed to standardizing our monitoring of subsurface $P$ fluxes across various hydrologic and management regimes (e.g., Radcliffe et al., 2015), which should include measuring the full suite of geochemical and hydrological factors affecting P solubility and movement. These efforts would not only provide new observational data that could be applied to water quality model development and further P Index evaluations in artificially drained landscapes but could also build on the preliminary findings reported herein.

\section{References}

Benning, J.L., and C.S. Wortmann. 2005. Phosphorus indexes in four Midwestern states: An evaluation of the differences and similarities. J. Soil Water Conserv. 60:221-227.

Berg, W.A., S.J. Smith, and G.A. Coleman. 1988. Management effects on runoff, soil, and nutrient losses from highly erodible soils in the Southern Plains. J. Soil Water Conserv. 43:407-410.

Blann, K.L., J.L. Anderson, G.R. Sands, and B. Vondracek. 2009. Effects of agricultural drainage on aquatic ecosystems: A review. Crit. Rev. Environ. Sci. Technol. 39:909-1001. doi:10.1080/10643380801977966

Bolster, C.H., P.A. Vadas, A.N. Sharpley, and J.A. Lory. 2011. Using a phosphorus loss model to evaluate and improve Phosphorus Indices. J. Environ. Qual. 41:1758-1766. doi:10.2134/jeq2011.0457

Bryant, R.B., A.R. Buda, P.J.A. Kleinman, C.D. Church, L.S. Saporito, G.J. Folmar et al. 2012. Using flue gas desulfurization gypsum to remove dissolved phosphorus from agricultural drainage waters. J. Environ. Qual. 41:664671. doi: $10.2134 /$ jeq2011.0294

Buczko, U., and R.O. Kuchenbuch. 2007. Phosphorus indices as risk-assessment tools in the USA and Europe: A review. J. Plant Nutr. Soil Sci. 170:445460. doi:10.1002/jpln.200725134

Buda, A.R., P.J.A. Kleinman, M.S. Srinivasan, R.B. Bryant, and G.W. Feyereisen. 2009. Effects of hydrology and field management on phosphorus transport in surface runoff. J. Environ. Qual. 38:2273-2284. doi:10.2134/jeq2008.0501 
Butler, D.M., D.H. Franklin, M.L. Cabrera, L.M. Risse, D.E. Radcliffe, L.T. West, and J.W. Gaskin. 2010. Assessment of the Georgia Phosphorus Index on farm at the field scale for grassland management. J. Soil Water Conserv. 65:200-210. doi:10.2489/jswc.65.3.200

Chardon, W.J., and O.F. Schoumans. 2007. Soil texture effects on the transport of phosphorus from agricultural land in river deltas of Northern Belgium, The Netherlands and North-West Germany. Soil Use Manage. 23:16-24. doi:10.1111/j.1475-2743.2007.00108.x

Christianson, L.E., R.D. Harmel, D. Smith, M.R. Williams, and K. King. 2016. Assessment and synthesis of 50 years of published drainage phosphorus losses. J. Environ. Qual. 45:1467-1477. doi:10.2134/jeq2015.12.0593

Coale, F.J., J.T. Sims, and A.B. Leytem. 2002. Accelerated deployment of an agricultural nutrient management tool: The Maryland Phosphorus Site Index. J. Environ. Qual. 31:1471-1476. doi:10.2134/jeq2002.1471

DeLaune, P.B., P.A. Moore, D.K. Carman, A.N. Sharpley, B.E. Haggard, and T.C. Daniel. 2004. Evaluation of the phosphorus source component in the phosphorus index for pastures. J. Environ. Qual. 33:2192-2200. doi:10.2134/jeq2004.2192

Eghball, B., and J.E. Gilley. 2001. Phosphorus risk assessment index evaluation using runoff measurements. J. Soil Water Conserv. 56:202-206.

Feyereisen, G.W., P.J.A. Kleinman, G.J. Folmar, L.S. Saporito, T.R. Way, C.D. Church, and A.L. Allen. 2010. Effect of direct incorporation of poultry litter on phosphorus leaching from coastal plain soils. J. Soil Water Conserv. 65:243-251. doi:10.2489/jswc.65.4.243

Fiorellino, N.M., J.M. McGrath, P.A. Vadas, C.H. Bolster, and F.J. Coale. 2017. Use of Annual Phosphorus Loss Estimator (APLE) model to evaluate a Phosphorus Index. J. Environ. Qual. doi:10.2134/jeq2016.05.0203

Flores-López, F., Z.M. Easton, L.D. Geohring, P.J. Vermeulen, V. Haden, and T.S. Steenhuis. 2013. Factors affecting phosphorous in groundwater in an alluvial valley aquifer: Implications for best management practices. Water 5:540-559. doi:10.3390/w5020540

Ford, W.I., K.W. King, M.R. Williams, and R.B. Confesor. 2016. Modified APEX model for simulating macropore phosphorus contributions to tile drains. J. Environ. Qual. doi:10.2134/jeq2016.06.0218

Gburek, W.J., A.N. Sharpley, L. Heathwaite, and G.J. Folmar. 2000. Phosphorus management at the watershed scale: A modification of the phosphorus index. J. Environ. Qual. 29:130-144. doi:10.2134/ jeq2000.00472425002900010017x

Good, L.W., P. Vadas, J.C. Panuska, C.A. Bonilla, and W.E. Jokela. 2012. Testing the Wisconsin Phosphorus Index with year-round, field-scale runoff monitoring. J. Environ. Qual. 41:1730-1740. doi:10.2134/ jeq2012.0001

Han, K., P.J.A. Kleinman, L.S. Saporito, C. Church, J.M. McGrath, M.S. Reiter et al. 2015. Phosphorus and nitrogen leaching before and after tillage and urea application. J. Environ. Qual. 44:560-571. doi:10.2134/jeq2014.08.0326

Harmel, R.D., H.A. Torbert, P.B. Delaune, B.E. Haggard, and R.L. Haney. 2005. Field evaluation of three phosphorus indices on new application sites in Texas. J. Soil Water Conserv. 60:29-42.

Israel, D.W., D.L. Osmond, and J.C. Roberts. 2007. Potential impacts of implementation of the phosphorus loss assessment tool (PLAT) on the poultry industry in North Carolina: Case studies. J. Soil Water Conserv. 62:48-54.

Jesiek, J.B., and M.L. Wolfe. 2005. Sensitivity analysis of the Virginia Phosphorus Index management tool. Trans. ASAE 48:1773-1781. doi: $10.13031 / 2013.20011$

Johnson, A.M. 2004. Phosphorus loss assessment in North Carolina. North Carolina State Univ., Raleigh, NC.

Johnson, A.M., D.L. Osmond, and S.C. Hodges. 2005. Predicted impact and evaluation of North Carolina's phosphorus indexing tool. J. Environ. Qual. 34:1801-1810. doi:10.2134/jeq2005.0020

King, K.W., M.R. Williams, M.L. Macrae, N.R. Fausey, J. Frankenberger, D.R. Smith et al. 2015. Phosphorus transport in agricultural subsurface drainage: A review. J. Environ. Qual. 44:467-485. doi:10.2134/jeq2014.04.0163

Kleinman, P.J.A., A.L. Allen, B.A. Needelman, A.N. Sharpley, P.A. Vadas, L.S. Saporito et al. 2007. Dynamics of phosphorus transfers from heavily manured Coastal Plain soils to drainage ditches. J. Soil Water Conserv. 62:225-235.

Kleinman, P.J.A., C. Church, L.S. Saporito, J.M. McGrath, M.S. Reiter, A.L. Allen et al. 2015a. Phosphorus leaching from agricultural soils of the Delmarva Peninsula, USA. J. Environ. Qual. 44:524-534. doi:10.2134/ jeq2014.07.0301

Kleinman, P.J.A., D.R. Smith, C.H. Bolster, and Z.M. Easton. 2015b. Phosphorus fate, management, and modeling in artificially drained systems. J. Environ. Qual. 44:460-466. doi:10.2134/jeq2015.02.0090

Köhne, J.M., S. Köhne, and J. Šimůnek. 2009a. A review of model applications for structured soils: A) Water flow and tracer transport. J. Contam. Hydrol. 104:4-35. doi:10.1016/j.jconhyd.2008.10.002
Köhne, J.M., S. Köhne, and J. Šimůnek. 2009b. A review of model applications for structured soils: B) Pesticide transport. J. Contam. Hydrol. 104:36-60. doi:10.1016/j.jconhyd.2008.10.003

Langdale, G.W., R.A. Leonard, and A.W. Thomas. 1985. Conservation practice effects on phosphorus losses from Southern Piedmont watersheds. J. Soil Water Conserv. 40:157-161.

Lemunyon, J.L., and R.G. Gilbert. 1993. The concept and need for a phosphorus assessment tool. J. Prod. Agric. 6:483-486. doi:10.2134/jpa1993.0483

Leytem, A.B., J.T. Sims, and F.J. Coale. 2003. On-farm evaluation of a phosphorus site index for Delaware. J. Soil Water Conserv. 58:89-97.

Lu, S., H.E. Andersen, H. Thodsen, G.H. Rubæk, and D. Trolle. 2016. Extended SWAT model for dissolved reactive phosphorus transport in tile-drained fields and catchments. Agric. Water Manage. 175:78-90. doi:10.1016/j. agwat.2015.12.008

Maguire, R.O., and J.T. Sims. 2002. Measuring agronomic and environmental soil phosphorus saturation and predicting phosphorus leaching with Mehlich 3. Soil Sci. Soc. Am. J. 66:2033-2039. doi:10.2136/sssaj2002.2033

McDowell, L.L., and K.C. McGregor. 1980. Nitrogen and phosphorus losses in runoff from no-till soybeans. Trans. ASAE 23:643-648. doi: $10.13031 / 2013.34638$

McDowell, R.W., and L.M. Condron. 2004. Estimating phosphorus loss from New Zealand grassland soils. N. Z. J. Agric. Res. 47:137-145. doi:10.1080 /00288233.2004.9513581

McDowell, R.W., and A.N. Sharpley. 2001. Approximating phosphorus release from soils to surface runoff and subsurface drainage. J. Environ. Qual. 30:508-520. doi:10.2134/jeq2001.302508x

McGrath, J.M., F.J. Coale, and N.M. Fiorellino. 2013. University of Maryland phosphorus management tool: Technical users guide. Univ. of Maryland, College Park, MD. https://extension.umd.edu/sites/default/files/_docs/ articles/EB-405\%20UMD\%20Phosphorus\%20Management\%20 ToolTechnical\%20Users\%20Guide.pdf (accessed 25 Aug. 2016).

NC PLAT Committee. 2005. North Carolina phosphorus loss assessment tool: I. Model description and II. Scientific basis and supporting literature. North Carolina State Univ., Raleigh, NC. http://nutrients.soil.ncsu.edu/software/ ncanat/plat/PLAT_Science_behind_the_tool.pdf (accessed 1 Sept. 2016).

Nelson, N.O., and A.L. Shober. 2012. Evaluation of phosphorus indices after twenty years of science and development. J. Environ. Qual. 41:1703-1710. doi: $10.2134 /$ jeq2012.0342

Obour, A.K., M.L. Silveira, J.M.B. Vendramini, L.E. Sollenberger, and G.A. O'Connor. 2011. Fluctuating water table effect on phosphorus release and availability from a Florida Spodosol. Nutr. Cycl. Agroecosyst. 91:207-217. doi:10.1007/s10705-011-9456-y

Osmond, D.L., M.L. Cabrera, S.E. Feagley, G.E. Hardee, C.C. Mitchell, P.A. Moore et al. 2006. Comparing ratings of the southern Phosphorus Indices. J. Soil Water Conserv. 61:325-337.

Osmond, D., A. Sharpley, C. Bolster, M. Cabrera, S. Feagley, B. Lee et al. 2012. Comparing phosphorus indices from twelve southern U.S. states against monitored phosphorus loads from six prior southern studies. J. Environ. Qual. 41:1741-1749. doi:10.2134/jeq2012.0013

Penn, C., J. Bowen, J. McGrath, R. Nairn, G. Fox, G. Brown et al. 2016. Evaluation of a universal flow-through model for predicting and designing phosphorus removal structures. Chemosphere 151:345-355. doi:10.1016/j.chemosphere.2016.02.105

Pierson, S.T., M.L. Cabrera, G.K. Evanylo, H.A. Kuykendall, C.S. Hoveland, M.A. McCann, and L.T. West. 2001. Phosphorus and ammonium concentrations in surface runoff from grasslands fertilized with broiler litter. J. Environ. Qual. 30:1784-1789. doi:10.2134/jeq2001.3051784x

Radcliffe, D.E., J. Freer, and O. Schoumans. 2009. Diffuse phosphorus models in the United States and Europe: Their usages, scales, and uncertainties. J. Environ. Qual. 38:1956-1967. doi:10.2134/jeq2008.0060

Radcliffe, D.E., D.K. Reid, K. Blomback, C.H. Bolster, A.S. Collick, Z.M. Easton et al. 2015. Applicability of models to predict phosphorus losses in drained fields: A review.J.Environ. Qual. 44:614-628. doi:10.2134/jeq2014.05.0220

Reid, D.K., B. Ball, and T.Q. Zhang. 2012. Accounting for the risks of phosphorus losses through tile drains in a phosphorus index. J. Environ. Qual. 41:1720-1729. doi:10.2134/jeq2012.0238

Schoumans, O.F., M. Silgram, P. Groenendijk, F. Bouraoui, H.E. Andersen, B. Kronvang et al. 2009. Description of nine nutrient loss models: Capabilities and suitability based on their characteristics. J. Environ. Monit. 11:506514. doi: $10.1039 / \mathrm{b} 823239 \mathrm{c}$

Sharpley, A. 2013. Technical guidance for assessing phosphorus indices. SERAIEG 17. Southern Coop. Ser. http://saaesd.ncsu.edu/docs/Assessing\%20 P\%20Indices\%20SERA17.pdf (accessed 7 Mar. 2017).

Sharpley, A., D. Beegle, C. Bolster, L. Good, B. Joern, Q. Ketterings et al. 2012. Phosphorus indices: Why we need to take stock of how we are doing. J. Environ. Qual. 41:1711-1719. doi:10.2134/jeq2012.0040 
Sharpley, A., H.P. Jarvie, A. Buda, L. May, B. Spears, and P. Kleinman. 2013. Phosphorus legacy: Overcoming the effects of past management practices to mitigate future water quality impairment. J. Environ. Qual. 42: 13081326. doi: $10.2134 /$ jeq2013.03.0098

Sharpley, A.N. 1985. Depth of surface soil-runoff interaction as affected by rainfall, soil slope, and management. Soil Sci. Soc. Am. J. 49:1010-1015. doi:10.2136/sssaj1985.03615995004900040044x

Sharpley, A.N., T.C. Daniel, and D.R. Edwards. 1993. Phosphorus movement in the landscape. J. Prod. Agric. 6:492-500. doi:10.2134/jpa1993.0492

Sharpley, A.N., J.L. Weld, D.B. Beegle, P.J.A. Kleinman, W.J. Gburek, P.A Moore, and G. Mullins. 2003. Development of phosphorus indices for nutrient management planning strategies in the United States. J. Soil Water Conserv. 58:137-152.

Sims, J.T., A.S. Andres, J.M. Denver, and W.J. Gangloff. 1996. Assessing the impact of agricultural drainage on ground and surface water quality in Delaware: Final project report. Univ. of Delaware, Newark, DE.

Sims, J.T., R.O. Maguire, A.B. Leytem, K.L. Gartley, and M.C. Pautler. 2002. Evaluation of Mehlich 3 as an agri-environmental soil phosphorus test for the Mid-Atlantic United States of America. Soil Sci. Soc. Am. J. 66:20162032. doi: $10.2136 /$ sssaj2002.2016

Sims, J.T., A.L. Shober, K.L. Clark, A.B. Leytem, and F.J. Coale. 2016. The Delaware phosphorus site index technical guidance manual. Univ. of Delaware. Newark, DE. http://extension.udel.edu/factsheets/de-phosphorus-siteindex-technical-guidance-manual/ (accessed 1 Sept. 2016).

Sims, J.T., R.R. Simard, and B.C. Joern. 1998. Phosphorus loss in agricultural drainage: Historical perspective and current research. J. Environ. Qual. 27:277-293. doi:10.2134/jeq1998.00472425002700020006x

Skaggs, R.W., M.A. Breve, and J.W. Gilliam. 1994. Hydrologic and water-quality impacts of agricultural drainage. Crit. Rev. Environ. Sci. Technol. 24:1-32. doi:10.1080/10643389409388459

Skaggs, R.W., R.O. Evans, and G.M. Chescheir. 2004. Simple methods for predicting annual subsurface drainage and surface runoff from drained lands. In: R. Cooke, editor, Drainage VIII: Proceedings of the 8th International Symposium, Sacramento, CA. 21 Mar. 2004. ASAE, St. Joseph, MI. p. 367-376.

Soileau, J.M., J.T. Touchton, B.F. Hajek, and K.H. Yoo. 1994. Sediment, nitrogen, and phosphorus runoff with conventional-tillage and conservation-tillage cotton in a small watershed. J. Soil Water Conserv. 49:82-89.

Sonmez, O., G. Pierzynski, L. Frees, B. Davis, D. Leikam, D. Sweeney, and K. Janssen. 2009. A field-based assessment tool for phosphorus losses in runoff in Kansas. J. Soil Water Conserv. 64:212-222. doi:10.2489/jswc.64.3.212
Staver, K.W., P. Kleinman, S. Ator, A. Buda, J.T. Sims, and J. Meisinger. 2014. A review of agricultural P-dynamics in the Chesapeake Bay Watershed Model. Chesapeake Bay Program, Edgewater, MD.

Strock, J.S., P.J.A. Kleinman, K.W. King, and J.A. Delgado. 2010. Drainage water management for water quality protection. J. Soil Water Conserv. 65:131A-136A. doi:10.2489/jswc.65.6.131A

Toor, G.S., and J.T. Sims. 2015. Managing phosphorus leaching in MidAtlantic soils: Importance of legacy sources. Vadose Zone J. 14(12):1-12. doi:10.2136/vzj2015.08.0108

USDA-NRCS.2004.Part630:Hydrology.Chapter 10:Estimation ofdirectrunoff from storm rainfall. Nat. Eng. Handb. USDA-NRCS, Washington, DC. http://directives.sc.egov.usda.gov/OpenNonWebContent.aspx?content $=17752$.wba (accessed 1 Sept. 2016).

Vadas, P.A., P.J.A. Kleinman, A.N. Sharpley, and B.L. Turner. 2005. Relating soil phosphorus to dissolved phosphorus in runoff. J. Environ. Qual. 34:572580. doi: $10.2134 /$ jeq2005.0572

Vadas, P.A., M.S. Srinivasan, P.J.A. Kleinman, J.P. Schmidt, and A.L. Allen. 2007. Hydrology and groundwater nutrient concentrations in a ditch-drained agroecosystem. J. Soil Water Conserv. 62:178-188.

Vories, E.D., T.A. Costello, and R.E. Glover. 2001. Runoff from cotton fields fertilized with poultry litter. Trans. ASAE 44:1495-1502. doi: $10.13031 / 2013.7032$

Wieczorek, M. 2004a. Subsurface drains on agricultural land in the conterminous United States, 1992. Nat. Res. Inventory Conserv. Practice 606. USGS. https://water.usgs.gov/lookup/getspatial?nri92_cp606 (accessed 6 Mar. 2017).

Wieczorek, M. 2004b. Surface drainage, field ditches on agricultural land in the conterminous United States, 1992. Nat. Res. Inventory Conserv. Practice 607. USGA. https://water.usgs.gov/lookup/getspatial?nri92_cp607 (accessed 6 Mar. 2017)

Wieczorek, M. 2004c. Surface drainage-main or lateral on agricultural land in the conterminous United States, 1992. Nat. Res. Inventory Conserv. Practice 608. USGS. https://water.usgs.gov/lookup/getspatial?nri92_ cp608 (accessed 6 Mar. 2017).

Williams, M.R., K.W. King, G.A. LaBarge, and R.B. Confesor, Jr., and N.R. Fausey. 2017. Edge-of-field evaluation of the Ohio phosphorus risk index. J. Environ. Qual. doi:10.2134/jeq2016.05.0198

Wolfe, M.L., J. Pease, L. Zelazny, L. Daniels, and G. Mullins. 2005. Virginia phosphorus index version 2.0 technical guide. Virginia Tech, Blacksburg, VA. https://efotg.sc.egov.usda.gov/references/public/VA/ VirginiaPIndex.pdf (accessed 1 Sept. 2016). 